Discussion

Papers

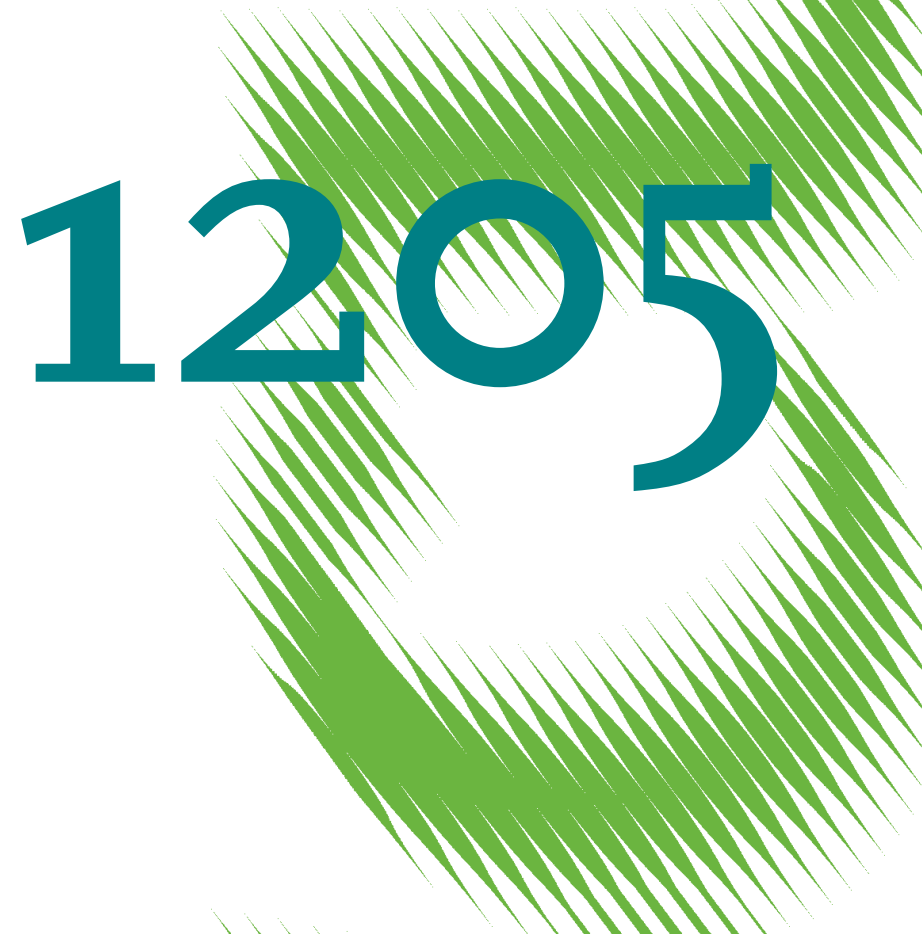

Do Parties Matter?

Estimating the Effect of Political

Power in Multi-party Systems 
Opinions expressed in this paper are those of the author(s) and do not necessarily reflect views of the institute.

IMPRESSUM

(C) DIW Berlin, 2012

DIW Berlin

German Institute for Economic Research

Mohrenstr. 58

10117 Berlin

Tel. $+49(30) 89789-0$

Fax +49 (30) $89789-200$

http://www.diw.de

ISSN print edition $1433-0210$

ISSN electronic edition 1619-4535

Papers can be downloaded free of charge from the DIW Berlin website:

http://www.diw.de/discussionpapers

Discussion Papers of DIW Berlin are indexed in RePEc and SSRN:

http://ideas.repec.org/s/diw/diwwpp.html

http://www.ssrn.com/link/DIW-Berlin-German-Inst-Econ-Res.html 


\title{
Do parties matter? \\ Estimating the effect of political power in multi-party systems
}

\author{
Ronny Freier* Christian Odendahl ${ }^{\dagger}$
}

April 17, 2012

\begin{abstract}
This paper estimates the effect of political power on tax policies in municipal councils under a proportional election system. The main challenge in estimating the causal effect of parties on policy is to isolate the effect of power from underlying voter preferences and the selection effect of parties. We use an instrumental variable approach where close elections provide the exogenous variation in our variable of interest: voting power. Using data from German municipalities in the state of Bavaria, our estimation results suggest that power does matter. Somewhat surprisingly, the center-left party SPD is found to lower all three locally controlled taxes, whereas The Greens increase both property taxes considerably. These results remain robust across a range of specifications. What is more, the effect of the SPD is confirmed by a simple regression discontinuity estimation of mayors in these local governments.
\end{abstract}

Keywords: $\quad$ local taxation, local election, municipality data instrumental variable approach

JEL classification: H10, H11, H77

Acknowledgments: We would like to thank Florian Ade, Tim Besley, Tore Ellingsen, Jon Fiva, Olle Folke, Peter Haan, Magnus Johannesson, Juanna Joenson, Henrik Jordahl, Torsten Persson, Per Pettersson-Lidbom, Imran Rasul, Viktor Steiner and David Strömberg as well as seminar and conference participants at Mannheim University, Tilburg University, Wissenschaftszentrum Berlin, DIW Berlin, Stockholm School of Economics, Uppsala University, EEA/ESEM (Oslo), EPCS (Rennes), ZEW Mannheim, BeNA Berlin and UCL for helpful comments and suggestions. We would also like to thank Helke Seitz, Jenny Freier and Heike Hauswald who provided excellent research assistance. Ronny Freier would like to thank the Hedelius foundation for funding the research visit to Princeton University and the Jan Wallander and Tom Hedelius Foundation for generous financial support. Christian Odendahl would like to thank the Hedelius foundation for funding the research visit to the London School of Economics. The usual disclaimer applies.

*DIW Berlin. (corresponding author) Mohrenstrasse 58, 10117 Berlin. rfreier@diw.de.

†Stockholm University. christian.odendahl@ne.su.se. 


\section{Introduction}

Does political power matter for policy? In a majoritarian system, this question is usually equivalent to: "Does it matter who wins the election?" The reason is that, after Duverger's law, a two-party system is likely to emerge. ${ }^{1}$ In a proportional election system, however, the question is more complex. We frequently observe a multitude of parties, and political power or "winning an election" is harder to measure and investigate.

We use the concept of "voting power" and estimate how changes in the voting power of parties affect policies. We use close election outcomes, that is, voting power changes that were the result of very close seat gains and losses, as a source of exogenous variation. Applied to municipalities in the German state of Bavaria between 1996 and 2007, this approach reveals three key results. First, political power does matter. We find significant effects for most parties, that are robust across various specifications. Second, the big center-left party SPD is found to robustly lower taxes, which is somewhat surprising. We hypothesize that the dominant center-right party CSU may refrain from tax competition because of its closer ties to other tiers of government. Finally, (weighted) voting power is a better measure than seat shares, which seems to be a noisy representation of power.

Three aspects of our paper need further introduction: the concept of voting power, the source of exogenous variation and the data. When measuring the influence of parties, it may seem natural to just use seat shares in the council. However, such a measure leaves out important aspects of power. For instance, if gaining or losing a seat does not shift the coalition options of parties in any meaningful way, the power of parties should not change either. Another example is a party that does not gain or lose a seat. If other parties change seats in such a way that new coalition options emerge, the power of the party without seat changes may increase or decrease as well.

In political science, a common measure is voting power. We will use the purely probabilistic measure of voting power after Penrose (1946) and Banzhaf (1965). ${ }^{2}$ In essence, this measure looks at all possible coalitions involving, say, party A and deducts whether it is pivotal for these coalitions, that is, whether they are no longer winning coalitions without party A. The share of coalitions in which party A is pivotal is the power measure. In order to make that an index, it is normalized by the total amount of power in this council.

\footnotetext{
${ }^{1}$ For a historical overview of the discovery and discussion of Duverger's law, see Riker (1982).

${ }^{2}$ See Felsenthal and Machover (1998) for details on voting power.
} 
In a two-party system voting power will either be one or zero, depending on who has the greater seat share. Thus, there is a simple mapping of seat shares to voting power. For multi-party systems on the other hand, voting power may differ substantially from seat shares. As an introductory example, consider three parties, where two big parties have $48 \%$ each, and the third party has only $4 \%$. Their relative voting power will be one third each because each party is equally useful in forming a winning coalition.

We take the Banzhaf index, as it is commonly called, one step further. Usually, the index considers all coalitions equally likely. A right-wing party may therefore be somewhat powerful according to this index, even if all its possible coalition partners are socialist parties. We weight the power index by how likely coalitions between the parties are to form, based on their position in the policy space. This weighted index will therefore reflect the power to influence policy decisions more realistically.

Naturally, no measure of power comes without criticism, and the Banzhaf index is no exception. ${ }^{3}$ However, its computational ease and how widely it is used and accepted in the literature make it a useful starting point for our analysis.

Next, we provide some further introduction on our identification strategy. To estimate the causal effect of political power on policy, we need to overcome a fundamental endogeneity problem: the correlation of political power with (unobserved) voter preferences. The observation that, say, a pro-business party obtains a certain amount of voting power in a town council and that the local business trade tax is below average in this town does not imply causality of political power of this party on tax rates. For the same underlying preferences, a center-left party may have chosen similar tax rates in order to target the local median voter.

Ideally, we would like to run an experiment where we assign political power randomly to parties across municipalities. In the perfect experiment, voter preferences are similar on average in treatment and control group and we could measure the causal effect of higher voting power for a specific party. This is (and should be) impossible.

In the absence of experimental data, a new literature has emerged in political economics that applies techniques from the program evaluation literature. Because political institutions are often rule-based - elections, of course, but also population thresholds and others - regression discontinuity designs (RDD) and instrumental variable approaches have become popular. We will use the fact that voting power changes

\footnotetext{
${ }^{3}$ We will discuss some criticisms in section 3.1 .
} 
when parties barely lose or gain seats to instrument for voting power. ${ }^{4}$ Because we only use the variation in power that was the result of very close election outcomes, this variation is arguably exogenous.

Pettersson-Lidbom (2008) and Lee, Moretti, and Butler (2004) were the first to use an RDD to estimate the effect of parties on policy. Lee, Moretti, and Butler (2004) estimate the effect of party affiliation in the US House of Representatives on policy. They exploit the fact that the identity of the winner jumps at $50 \%$ of the votes. They show significant effects of party affiliation (Democrat or Republican) on the voting record of the representatives. Pettersson-Lidbom (2008) studies the policy effects of having a left-block majority (of one or more parties) in Swedish municipalities. The identification is also an RDD at the $50 \%$ vote margin. He finds significant effects of block majorities on tax rates and different spending categories. Ferreira and Gyourko (2009) investigate the effect of having a Democratic or a Republican mayor in office in US cities on fiscal outcomes in a similar RDD framework. They find effects of the mayor on policy only if Tiebout competition between municipalities is weak. ${ }^{5}$

In all these studies, two sides compete for an office or the majority. The winning threshold is therefore simply at $50 \%$. This has two consequences for the research design: First, there is a simple mapping of seat shares on political power, as discussed above. Second, it is possible to use a simple RDD framework at a fixed threshold. While we tackle the first by using (weighted) voting power - defining blocks like in Pettersson-Lidbom (2008) is impossible in German local politics - we need a technical solution for the second: in a proportional system, there are no fixed thresholds. We shortly introduce our solution here.

In a proportional election system, the electorate votes on specific parties and their vote shares need to be translated into seats. There are different mathematical techniques to do that, but they have one thing in common: the seat share of any one party depends not only on its own vote share, but also on the composition of the entire council. As an example, we assume a council with ten seats, three parties and 100 voters. ${ }^{6}$ If the result is 35 votes for party A, 33 for B, and 32 for $\mathrm{C}$, the seat allocation

\footnotetext{
${ }^{4}$ Voting power does not always change when seats switch. We will come back to this issue in section 3.1.

${ }^{5}$ The approach to use close elections has recently been criticized in the literature. Caughey and Sekhon (2011) for instance show that close election outcomes in the US House are not random. Grimmer, Hersh, Feinstein, and Carpenter (2011) is another example. In our case, however, we consider close changes in voting power on the local level that are arguably impossible to predict for either voters or politicians. We provide some further evidence that pre-election policies are not affected by subsequent close outcomes in voting power.

${ }^{6}$ We assume the so-called Hare-Niemeyer seat allocation function.
} 
will be $4,3,3$. If the result is $35,36,29$, the seat distribution will be $3,4,3$, even though party A received as many votes as before.

In order to use an RDD or an instrumental variable estimation, we need to know which elections were in fact close, and which were not. Folke (2010) use the seat allocation function directly and measures the minimum amount of votes that need to be changed in order to alter the seat allocation. He finds an effect of seat shares for small parties on local environmental and immigration policy. He finds no effect of seat shares on taxes. In a recent paper, that was written simultaneously to ours, Fiva, Folke, and Sorensen (2011) apply the same method to seat shares in Norway and uncover effects on taxes and user charges.

Our paper focuses on voting power instead of seat shares, and uses a different method to isolate close elections. In our approach, we repeatedly perturb the vector of votes for each observation by adding a random variable to the votes of each party. We then simulate the new seat allocation and calculate the voting power of parties accordingly. This allows us to observe changes in voting power. Observations whose voting power distribution changes often during these simulations are considered close. For these close observations, we calculate the average gain or loss of voting power for each party when voting power does change. This average change is then used as an instrument for actual voting power.

Our numerical approach has the advantage that it can be easily implemented across a wide range of election methods, and can incorporate different assumptions about the voter migration between parties. While we focus on the German state of Bavaria in our main results, we also provide estimations for Thuringia and Hesse, which both have different seat allocation rules. More generally, our idea to use repeated random perturbations can be used in other circumstances as well. For instance, it can be used to detect the decisive thresholds in complex contest-like evaluation problems.

We have compiled a new data set that combines information on both election outcomes and fiscal data at the municipal level. The data covers two recent municipal elections in three German states: Bavaria, Thuringia and Hesse. ${ }^{7}$ The election data contains information on total votes and seats for all parties. In addition, we have yearly information on the three local tax rates (trade tax as well as two property taxes) for each municipality.

\footnotetext{
${ }^{7}$ We have to restrict the analysis to those three states due to limitation in data availability.
} 
The paper is organized as follows. In section 2, we outline the electoral rules, gives some background on the responsibilities of German municipalities and presents the data. Section 3 presents our empirical strategy, including the methodological background on how to define close elections and how to calculate voting power. Section 4 contains the results before the analysis is concluded in section 5 .

\section{Institutional background and data}

In this section, we describe the seat allocation functions that are used in German municipalities and give some institutional background on local politics in Germany.

\subsection{Elections and electoral rules}

In Germany, there are four tiers of government: federal, state, county and municipality. Our focus is on municipal elections and policies. In municipalities, the legislative body is the council (Gemeinderat or Stadtrat, depending on town size). It is elected every 6 years in Bavaria, and every 5 years in Thuringia and Hesse, in a proportional election system. The parties that participate are the 5 major parties in Germany: the center-right party (called CSU in Bavaria, and CDU in Thuringia and Hesse), the center-left party (SPD), a pro-market party (FDP), The Greens and a socialist party (The Left). ${ }^{8}$ In addition, there are usually local parties that form independently of the major parties. The Free Voters (Freie Wähler), while purely local and independent, are often member of a collective of Free Voter parties, either regional or on a state level.

The mayor of the municipality is elected by the public as well. Often, the timing of the elections coincide. The mayor is head of the administration and also a voting member of the council in Bavaria and Thuringia. Even though the mayor proposes the budget and generally sets the agenda, the council is free to change it and has ultimate power over legislation.

In every proportional election system, a seat allocation function is used to distribute (discrete) seats to parties based on their votes. This seat allocation function is by

\footnotetext{
${ }^{8}$ The Christlich Demokratische Union (CDU) and the Christlich-Soziale Union (CSU) is the party of the current federal chancellor Angela Merkel and Helmut Kohl, the Sozialdemokratische Partei Deutschlands (SPD) is the party of Gerhard Schröder and Willy Brandt, the Freie Demokratische Partei (FDP) is the party of Hans-Dietrich Genscher, Die Gruenen (The Greens) is the party formed from the environmental movement in the begining of the 1980s and Die Linke (The Left) is the former PDS which was founded as the successor party of the Socialist Unity Party (SED) in former East Germany.
} 
design a step-wise function since there are more votes than seats. The locations of these steps for party A, however, are not predetermined. They are jointly determined by all arguments of the seat allocation function: the votes of all parties, the sum of those votes and the council size. In what follows, we first describe the seat allocation functions used in German municipalities before returning to the question of where the seat thresholds for a party A lie.

The states choose the allocation method for their municipalities such that all municipalities in a certain state have the same seat allocation function. There are two different seat allocation functions used in German municipalities.

The first is the largest remainder method (or Hare-Niemeyer method), used in Thuringia and Hesse, among others. The first step in this method is to calculate the Hare quota: total votes divided by total seats. This gives the "price" in terms of votes that a party has to "pay" for one seat. Then the votes of all parties are divided by this price. The resulting quotient is the exact number of seats that each party should receive in case of perfect proportionality. However, it is rarely, if ever, an integer. Therefore, the largest remainder method allocates the seats according to the integer of this quotient. This results almost always in at least one remaining seat. The remaining seat(s) are then distributed according to the rank order of the remainders of each party.

The second method, used in Bavaria, is the highest averages method (or d'Hondt method). ${ }^{9}$ This method proceeds just as the largest remainder method by calculating the price of a seat (the Hare quota), dividing each party's votes by this price and then distributing seats according to the integer of the resulting quotient. ${ }^{10}$ As under Hare-Niemeyer, there will be at least one remaining seat. Under the d'Hondt method, however, the price of the seats is lowered in small increments in order to distribute the remaining seat(s). In other words, the procedure is repeated with a lowered price and seats are allocated according to the integer until the procedure results in a complete allocation of all seats. ${ }^{11}$ We refrain from laying out the additional complications in the Bavarian election rules. ${ }^{12}$

\footnotetext{
${ }^{9}$ There are several highest averages methods, for instance the method of Sainte-Lague. Since only the method of d'Hondt is used in Germany, we will describe only this method.

${ }^{10}$ There are several different ways of reaching the final seat allocation in the highest averages method. The other common form is the use of a divisor series. Both yield the exact same result.

${ }^{11}$ The two approaches may lead to different seat allocations since the d'Hondt method slightly favors larger parties. The intuition is as follows: the "price" of a seat in the d'Hondt method is lowered until the distribution of seats according to the integer leads to a full distribution of seats. If we regard the votes of a party as its budget, lowering the price is best for the party that already has the most seats - compared to the Hare-Niemeyer method where just the remainders are compared.

${ }^{12}$ The major complication being that parties can form joint list for the purpose of the election
} 
Now we return to the question of where a seat threshold lies for party A. As the description above explains (and the example in the introduction shows), the number of seats for party A depend not only on its own votes, but also on the distribution of votes among its competitors. However, we know that there are thresholds in all dimensions of the vote vector. In order to determine whether an election was "close", we need to check how close a party was to them. Before we explain in detail in section 3 how we can accomplish that, we shortly introduce the responsibilities of German municipalities, and the data.

\subsection{Responsibilities of German municipalities}

The local government is head of the administration of municipalities. In Bavaria, local governments manage a yearly budget of about 1560 Euro per capita on average. This amounts to roughly one third of total per capita government spending in Germany. Moreover, two thirds of all investment spending in Germany is allocated by municipalities, and they employ around $40 \%$ of all state employees. ${ }^{13}$

The municipalities set three tax rates whose revenues completely accrue to them: a local business tax and two types of property taxes. The local budget also contains a share of the income tax revenue raised in the municipality and a part of the VAT revenue. Setting the rates for those two taxes is however not a municipal responsibility. Another part of their budget is federal or state allocated funds that the municipalities administer, e.g. for public schools or social services.

The municipalities spend their revenues in the following areas:

- general administration

- public order

- public schools, cultural centers and services, social services (elderly care, immigration housing, child care, youth services)

- sport and recreation

- infrastructure investments (housing projects, roads), public transport, business development, management of public firms

only. In a second step, their joint seats are separated according to an "internal" d'Hondt method as if the list were the parliament.

${ }^{13}$ See Bundesbank (2007). 
However, the division of tasks between the tiers is often complex: which tier of government pays for the service or investment, or for part of it, which tier enacts the law or by-law, which tier administers the service and so forth. More often than not, each of these tasks is itself divided between the tiers of government. Thus, the degree of discretion for the municipality varies by field. While municipalities are, for example, completely free to decide about cultural or recreational institutions, most social services have to be administered within clearly defined laws and by-laws. Those rules are to a large extent enacted by the federal or state government and the municipalities use mandated funds from higher tiers.

This leads to very high variation in spending variables, which is arguably too much for the small changes in voting power that we identify. Therefore, we focus on tax rates. They are the sole responsibility of municipalities and show less variation than spending.

\subsection{Data}

We have compiled a new data set that combines information on both election outcomes and fiscal data on the municipality level in Germany. We use data from three German states: Bavaria and Hesse from the Western part and Thuringia from the Eastern part.

Table 1 shows the descriptive statistics for the political variables. For each state we have election data on two municipal elections. There are between 400 and 2050 municipalities in each state. The center-right CDU and the center-left SPD participate in most elections in the western states and in many communities in the East. The Greens and the pro-market FDP participate in much less elections. For the socialist left, which had a strong focus on eastern Germany until recently, we only observe data in Thuringia.

Table 2 shows the descriptive statistics for the tax multipliers. For all these outcomes, we took the average over the period between two elections. We left out the data from the election years because elections are usually not at the end of a fiscal year. ${ }^{14}$

The tax multipliers require some explanation. ${ }^{15}$ The local business tax is a tax on business income, where "business" includes all companies and firms as well as self-

\footnotetext{
${ }^{14}$ In cases where we do not have data for the whole period, for instance the election in 2004 in Thuringia, we took the average over all years that we had data for. Our data on fiscal outcomes starts in 1998.

${ }^{15}$ See Bundesfinanzministerium (2012), and Bundesbank (2007) for details in German. The website of the Bundeszentralamt fuer Steuern provides further information in English (Bundeszentralamt fuer Steuern (2012)).
} 
Table 1: Data set - descriptive statistics for the election data

\begin{tabular}{|c|c|c|c|c|c|c|}
\hline \multirow{2}{*}{$\begin{array}{l}\text { Election } \\
\text { State/Year }\end{array}$} & \multirow[t]{2}{*}{ Observations } & \multicolumn{5}{|c|}{ Participation rate in the elections for } \\
\hline & & $\mathrm{CDU}$ & SPD & FDP & Greens & Left \\
\hline Bay 1996 & 2020 & 0.83 & 0.65 & 0.07 & 0.17 & 0.00 \\
\hline Bay 2002 & 2010 & 0.83 & 0.64 & 0.08 & 0.15 & 0.00 \\
\hline Thur 1999 & 766 & 0.69 & 0.38 & 0.18 & 0.01 & 0.32 \\
\hline Thur 2004 & 716 & 0.66 & 0.33 & 0.14 & 0.01 & 0.29 \\
\hline Hes 1997 & 417 & 0.98 & 1.00 & 0.24 & 0.55 & 0.00 \\
\hline Hes 2001 & 414 & 0.98 & 0.99 & 0.50 & 0.49 & 0.00 \\
\hline
\end{tabular}

Notes: The table shows the number of observations for each election in the first column. The remaining columns show how often the different parties participated (in shares) in the respective elections. The abbreviations for the states are: Thur - Thuringia, Hes Hesse, Bay - Bavaria. The abbreviations for the party are: CDU - conservative centerright (Christlich Demokratische Union, CSU in Bavaria), SPD - socialdemocrats centerleft (Sozialdemokratische Partei Deutschlands, FDP - pro-market (Freie Demokratische Partei), The Greens - green party (Buendnis 90/Die Gruenen), The Left - socialist party (Die Linke former Partei des Demokratischen Sozialismus). Source: Own calculations.

Table 2: Data set - descriptive statistics for the tax rates

\begin{tabular}{lcrrrr}
\hline \hline \multicolumn{1}{c}{ Fiscal Category } & Observations & Mean & Std. dev & Min & Max \\
\hline Trade tax multiplier & 4030 & 322.0 & 21.7 & 240 & 437.5 \\
Property tax A multiplier & 4030 & 326.6 & 55.8 & 150 & 766.7 \\
Property tax B multiplier & 4030 & 321.4 & 48.3 & 150 & 766.7 \\
\hline
\end{tabular}

Notes: The table shows the descriptive statistics for the fiscal data used as outcome variables in the analysis. The information on the local taxes refer to the respective multipliers in the tax formula. These multipliers are bounded between $0-800$ (in the period of observation). Source: Own calculations.

employed that do not belong to the so-called liberal professions (Freiberufler). ${ }^{16}$ The tax payment is calculated based on federal tax law and then multiplied by the local tax multiplier that the municipality sets. This trade tax is separate from the federal business income tax. The multipliers range from 0 to $800,{ }^{17}$ and the actual tax rates for this trade tax is in the range of about $9 \%$ to $28 \%$. The property taxes in Germany are ad valorem taxes where tax $\mathrm{A}$ is applied to agricultural property and tax $\mathrm{B}$ to all other property. Again, the tax payment is calculated based on federal law and then multiplied by the municipal tax multiplier.

\footnotetext{
${ }^{16}$ These include for example artists, lawyers, scientists, teachers, accountants, doctors, all medical therapists, architects, journalists, photographers and engineers.

${ }^{17}$ During a reform in 2003 a statutory federal minimum of 200 for the trade tax multipliers was implemented. However, there was only a handful of communities that were directly affected by this reform.
} 


\section{Empirical Strategy}

In this section, we outline the empirical strategy. We start with defining voting power, then explain how we find close elections before defining our instrument for voting power and discussing our regression.

\subsection{Voting power}

As outlined in the introduction, we use the voting power measure after Penrose (1946) and Banzhaf (1965). This is a purely probabilistic measure, which is defined as follows. ${ }^{18}$ For $n$ different parties in a council, there are $2^{(n-1)}$ possible coalitions that, say, party A could be a part of. ${ }^{19}$ Moreover, party A is said to be critical in a coalition, if this coalition (with A) is a winning coalition, but without $\mathrm{A}$ it is not.

Then the (absolute) voting power of party A is defined as

$$
\beta_{a}=\frac{\eta_{a}}{2^{(n-1)}}
$$

where $\eta_{a}$ is the number of times party $\mathrm{A}$ is critical. If we assume that all coalitions are equally likely to form, then $\beta_{a}$ measures the a priori probability of party $\mathrm{A}$ to be in a position to change the fate of a decision. It is this interpretation that makes this measure of voting power a measure of influence on policy.

Voting power measured in this way does not necessarily add up to one. To construct an index of voting power that adds up to one, we divide the $\eta_{a}$ not by $2^{(n-1)}$, but by the sum of the $\eta_{j}$ s:

$$
\beta_{a}^{\prime}=\frac{\eta_{a}}{\sum_{j \in N} \eta_{j}}
$$

This index forms the basis of our voting power measure. ${ }^{20}$ For an issue as delicate as power, there is some justified criticism of this power index. Snyder, Ting, and Ansolabehere (2005) for instance, criticize that the Banzhaf index is somewhat at odds with microeconomic intuition. Their argument is that a player that commands $k$ voting weights should have the same "price" (and thus, power) as the sum of $k$ players

\footnotetext{
${ }^{18}$ The definition and discussion of voting power is based on Felsenthal and Machover (1998).

${ }^{19}$ A set $N$ with $n$ elements, has a power set $2^{N}$ with $2^{n}$ elements (which includes the empty set). The power set of all parties except party A has therefore $2^{(n-1)}$ elements, including the empty set. If we add party A to all these possible coalitions, we have the set of all possible coalitions that involve party A.

${ }^{20}$ We prefer the relative voting power measure as it reflects the relative strength of a certain party to influence policies.
} 
with $\frac{1}{k}$ voting weight each, as perfect substitutes in a competitive environment have the same price. The Banzhaf index on the other hand gives those with larger voting weights a disproportionately higher voting power. ${ }^{21}$ The reason for this difference is that the Banzhaf index assumes that all coalitions are equally likely to form. In a non-cooperative bargaining approach like that in Snyder, Ting, and Ansolabehere (2005), however, those coalitions form that are cheapest for the formateur. They show that expected payoffs in this setting are more in line with voting weights than with voting power as measured by the Banzhaf index.

However, there is one important distinction to be made for empirical research. ${ }^{22}$ If we want to analyze the formation of coalitions, we need to consider the non-cooperative bargaining situation of dividing-the-dollar issues like cabinet posts. If, on the other hand, we want to study policy outcomes that are the result of many different council decisions, it is more appropriate to use voting power. This aspect is further supported by the realities in German local governments where informal coalitions may exist but new issue-specific coalitions can form. ${ }^{23}$

Therefore, voting power is the appropriate measure for our empirical approach. However, for policy purposes it could also be problematic that the voting power measure assumes that all coalitions are equally likely to form. ${ }^{24}$ The reason is that we are interested in measuring the power of parties to affect policies. A standard voting power gain for a conservative party may be less useful if all potential coalition partners are socialist parties. In addition to using the standard measure, we also weight the coalitions by the likelihood of their formation, that is, how close they are in the policy space. ${ }^{25}$

\footnotetext{
${ }^{21}$ As an example, consider the 11 seat council with 4 parties and the following seats: 4,3,2,2. The (minimum integer) voting weights are $2,1,1,1$. The voting power index, however, is $\frac{1}{2}, \frac{1}{6}, \frac{1}{6}, \frac{1}{6}$.

${ }^{22}$ Ansolabehere, Snyder, Strauss, and Ting (2005) make this distinction as well.

${ }^{23}$ To explain this distinction in a little more detail, we assume two scenarios: the overall level of spending and taxes, and a one-time spending targeted on a specific constituency or a one-time gain from being in office for the politicians. In the first case, the parties decide on many different policy issues where all kinds of coalitions could form. If we assume a large $n$-dimensional policy space and no way for parties to commit to a certain coalition, there will be many different coalitions that form, and parties that are decisive for many of these coalitions will carry more weight. Hence, voting power may be the best measure in this scenario. In one-off divide-the-dollar decision on the other hand the parties engage in a bargaining game in which smaller players may get more than their proportional weight as they are the cheapest to form a coalition with. Large players, with a high weight of their own may nevertheless suffer as they are expensive to include in a coalition. See Persson and Tabellini (2002), chapters 5 and 7 for more a simple exposition of these issues. This is why Snyder, Ting, and Ansolabehere (2005), who study this second scenario, find payoffs to be proportional to voting weights, contrary to what voting power would entail.

${ }^{24}$ The standard voting power measure is used for example to analyze different voting rules, where it is very useful.

${ }^{25}$ Our reason for doing it is thus different from Snyder, Ting, and Ansolabehere (2005): we want
} 
In practice, we will locate parties in a one-dimensional policy space, which is often called the (socio-economic) left-right dimension. We use the locations derived in Pappi and Eckstein (1998) for German parties. The distance between two parties is then a measure of the likelihood of a policy coalition between the parties. This likelihood will be the weight of this coalition:

$$
w_{k j}=1-\left(d_{k j}\right)^{s}
$$

where $d_{k j}$ measures the distance between party $k$ and party $j$, and $s>1$ affects the curvature of our distance measure. It only measures the curvature because we normalize the distance between the most extreme parties to be unity. For those parties (like a strongly right-wing party and a communist party) the weight on their coalition will be zero, which implies that they do not receive any voting power from this coalition, even if it were a winning coalition and each of them were critical. ${ }^{26}$

Relative voting power with weights will then be calculated as:

$$
\beta_{a}^{\prime w}=\frac{\eta_{a}^{w}}{\sum_{j \in N} \eta_{j}^{w}}
$$

where

$$
\eta_{j}^{w}=\sum_{j: \text { critical }} w_{k j}
$$

$\eta_{j}^{w}$ is therefore the sum of all the weights of those coalitions in which party $j$ is critical. ${ }^{27}$

\subsection{Defining close elections}

In this section, we discuss how we define closeness of a seat allocation, and thus, a voting power outcome. We intend to use close elections as a source of exogenous variation in voting power, in order to separate this variation from variation in voter preferences.

We propose the following definition of closeness of elections. For each observation $i$ with vote vector $\mathbf{v}_{i}$ and the resulting (known) seat allocation, we add a vector of

to add realism to voting power when it comes to policy decisions, whereas they take into account the bargaining position for a one-off divide-the-dollar issue.

${ }^{26}$ If we have a coalition of three or more parties, the distance within this coalition will be equal to the distance between the two parties within that coalition that are farthest away from each other.

${ }^{27}$ Bilal, Albuquerque, and Hosli (2001) propose a similar approach to weighted relative voting power. 
random variables to the vector of votes. These random variables represent a weather shock, or popularity shocks. We then calculate the new seat allocation and the resulting power distribution from this perturbed vote vector and track whether the power of parties has changed. This procedure is repeated multiple times. An election is close if the power distribution changes often.

In practice we add a vector $\mathbf{r}_{i}$ of independently normally distributed random variables to the vote vector of observation $i$ with expectation zero and variance $\left(k v_{i}^{j}\right)^{2}$. The standard deviation of these random variables is thus $k$ percent of the votes of party $j$. This ensures that for a small party the perturbation is small. Power allocations for party $j$ in municipality $i$ are considered close, if in repeated perturbations of the vote vector, the voting power for this party $j$ changes more than $q \%$ of the time.

Next we discuss our choice of $q$ and its interpretation. For normally distributed random variables, roughly $\frac{1}{3}$ of the probability mass lies outside the interval of the mean plus/minus one standard deviation. Moreover, we observe from our perturbations that almost all power changes go in only one direction, not both. ${ }^{28}$ It follows that if we observe one additional seat for party $j$ in municipality $i$ in $\frac{1}{6}$ th of our perturbations, we know that roughly one standard deviation in vote change for this party was required for this change in seat allocation. ${ }^{29}$ When we vary the degree of closeness in later specifications, we will only change $k$ in the standard deviation of the random variables. The share $q$ will always be $\frac{1}{6}$ in order to allow for this interpretation. ${ }^{30}$

Our approach differs from that in Folke (2010) in that we propose a numerical, simulation-based and not an analytical solution to find close outcomes. There are two advantages. First, the implementation is substantially easier. Folke (2010) develops a complex algorithm to compute the minimal vote change. This algorithm is tailored to the specifics in Sweden and is not easily adjustable to variations in the electoral system. Specifically, it cannot be used without substantial adjustments in the electoral system in some of the German states. Our approach does not depend on the specifics of the electoral system, but can be applied to any system. Second, it is simple to implement different structures of randomness or restrictions. ${ }^{31}$

\footnotetext{
${ }^{28} \mathrm{It}$ is possible that a power allocation is close in both directions: for instance, if three parties have very similar remainders in the Hare-Niemeyer method. However, such situations occur only rarely for very small perturbations like the ones in the present paper.

${ }^{29}$ That does not mean that for every seat change one standard deviation vote gain or loss was necessary for the party in question. A seat change for party $A$ can be the result of vote changes for other parties, too. The interpretation given here only offers an idea of the magnitudes involved.

${ }^{30}$ If we use $k=2 \%$, a party that received 100 votes will be perturbed such that the vote count is between $[98,102]$ in about $66 \%$ of the cases and between $[96,104]$ in $95 \%$ of the cases.

${ }^{31}$ If, for instance, we know that a shock affects some parties, but not others, or that voters migrate
} 
Before we introduce how the information from the repeated perturbations will be used in the instrumental variable estimation, we want to highlight how our perturbation method may help in other contexts. ${ }^{32}$ While election outcomes and seat allocation mechanisms seem like the natural application for our method, it can also be used in a specific class of contest-like evaluation problems.

These evaluation problems comprise three components. First, the assignment of treatment must follow a contest-like procedure. In our case, we have parties competing for seats in an election. Further applications, e.g., could be athletes competing for medals as well as students competing for scholarships or admission. In general, any type of assessment center or relative ranking that determines treatment might be suitable for our new perturbation method.

Second, multiple random events must determine who gets treated. In this paper, we argue that the exact vote count of each and every participating party constitutes such random events. Similarly, the test score of a number of students or the weather conditions under which athletes compete could represent individual random influences. In sum, the outcome of the relative ranking contest must be subject to not just one (in which case it is simple to model) but many random events.

Finally, the mechanism which determines treatment needs to be complex. ${ }^{33}$ In our application, actual seats and voting power depend on the seat allocation mechanism in which the (partly) random election outcomes interact in a complex way. While the complexity of our problem seems unique at first hand, we believe that many contests indeed have similarly intricate allocation formulas. Examples of such allocation mechanisms could be the placement mechanisms used in schools, university or other professional assessment situations (consider the complexities of the Boston school choice mechanism, see Abdulkadiroglu and Soenmez (2003)) as well as any system that uses quotas or similar restrictions.

\footnotetext{
between neighboring parties in the event of a popularity shock, we can incorporate this in the covariance structure of the random variables.

${ }^{32}$ We are grateful to Olle Folke for pushing us to think further on these issues.

${ }^{33}$ Indeed, researchers have studied the case in which we have only the first two components, but no complex mechanism that determines the final treatment. Black, Galdo, and Smith (2005) draw the attention to an evaluation problem in which unemployed workers obtain the treatment (reemployment services) based on relative ranking. They make clear that instead of a single discontinuity point, we have to deal with an discontinuity frontier that shifts in each of the multiple ranking events that they observe. While the nature of that evaluation problem is indeed close to our setting, they have no need to perturb the score vector because the final allocation mechanism is simply to treat everybody above a (shifting) threshold.
} 


\subsection{Empirical specification}

In this section, we lay out our empirical specification. We start with some motivating remarks on why we use close election outcomes only, and then discuss our regression.

In general, the effect of parties on policy is hard to distinguish from the underlying preferences of the voters. Assume that we have parties $A, B$ and $C$, a vote vector $\mathbf{v}_{i}$, voting power shares $p_{i}^{j}$ and outcome $Y_{i}$ in municipality $i$. We would like to estimate the effects of the parties on policy outcome $Y_{i}$. Experimental data is impossible to obtain and OLS of the outcome on voting power shares is biased by underlying voter preferences if we estimate

$$
Y_{i}=\alpha+\beta_{B} p_{i}^{B}+\beta_{C} p_{i}^{C}+\mathbf{X}_{i} \gamma+e_{i}
$$

where $\mathbf{X}_{i}$ is a set of control variables like population, or time dummies. ${ }^{34}$ The error term in this equation contains not only a random component $w_{i}$ but also unknown voter preferences $\phi_{i}$ :

$$
e_{i}=w_{i}+\phi_{i}
$$

These voter preferences affect both the outcome and the voting power shares, as voter preferences are a main determinant of the election results. Therefore, $E\left(p_{i}^{j} e_{i}\right) \neq 0$ and the coefficients will be biased.

However, we could use the fact that the seat allocation function is a discontinuous function of the vote vector: a party can only gain a full seat, not a fraction of a seat. That in turn means, vote shares and voting power shares do not necessarily coincide. If we interpret vote shares as reflecting voter preferences, and voting power shares as our variable of interest, we could estimate

$$
Y_{i}=\alpha+\beta_{B} p_{i}^{B}+\beta_{C} p_{i}^{c}+f\left(\mathbf{v}_{i}\right)+\mathbf{X}_{i} \gamma+u_{i}
$$

The problem with this approach is that the function $f(\cdot)$ needs to capture the voter preferences $\phi_{i}$ correctly over the whole range of possible values for $\mathbf{v}_{i}$ - and for the interaction of the vote shares of all parties - in order for the voting power shares to be uncorrelated with the error term. Formally, the condition is

$$
E\left(p_{i}^{j} e_{i} \mid f\left(\mathbf{v}_{i}\right)\right)=0 .
$$

\footnotetext{
${ }^{34}$ Note that we leave out party A because voting power shares add up to one. For further discussion, see the bottom part of this section.
} 
It is hard to argue that we will be able to accomplish that. As explained in section 2.1 , the steps in the seat allocation function are not predetermined, but depend on the votes of all parties, the total votes and the council size. This in turn means that the steps could be anywhere in the vote vector space. Voting power makes it even more complex: some changes in seats affect voting power, sometimes even of parties whose seats have not changed, while others do not. The control function would have to be a polynomial of high order, and interacted in various ways, to capture the relationship between vote shares and policy correctly such that voting power shares only capture power.

We therefore suggest to use the step-wise nature of the seat allocation function in a different way: we only use observations where voting power was close to being changed for our identification. This relaxes the need to specify the whole function $f(\cdot)$ correctly. However, we still use a control function but the only two assumptions that we need to make are that $f(\cdot)$ is continuous at the steps, and that it is correctly specified close to these steps.

To see why, consider an extreme case where we have almost unlimited amounts of data. This implies that we can get arbitrarily close to voting power thresholds. If we are just one vote away from a change for each close observation that we identify, it is safe to argue that the averages that we calculate on both sides (for close voting power gains and losses) will be unbiased and any difference is the result of the change in power. This would obviate the need for a control function.

In figure 1, we draw the potential outcome functions and a hypothetical voting power threshold (the solid vertical line), using the votes for this party on the horizontal axis. ${ }^{35}$ Our interest lies in comparing $A$ and $B$, because the difference between the two is the causal effect of voting power on policy outcome $Y$. If we can get arbitrarily close to the threshold, we get unbiased estimates of $A$ and $B$.

Of course, we need to relax the assumption of unlimited data. However, we stay very close to the seat thresholds in our design. In figure 1, we stay between the dotted vertical lines. In these ranges we calculate averages on both sides, in the segments $a$ and $b$. Without any control function for the underlying relationship between the vote vector (the forcing variable) and the outcome variable, those averages will be biased: the average over all observations in $b$ will be too high, and too low in $a{ }^{36}$

\footnotetext{
${ }^{35}$ As outlined above, this is not entirely correct because thresholds depend on the whole vote vector, not only the votes of one party. The figure is therefore just for illustrative purposes.

${ }^{36}$ See Hahn, Todd, and Van der Klaauw (2001) for a formal treatment of this bias.
} 
Figure 1: Using the discontinuity

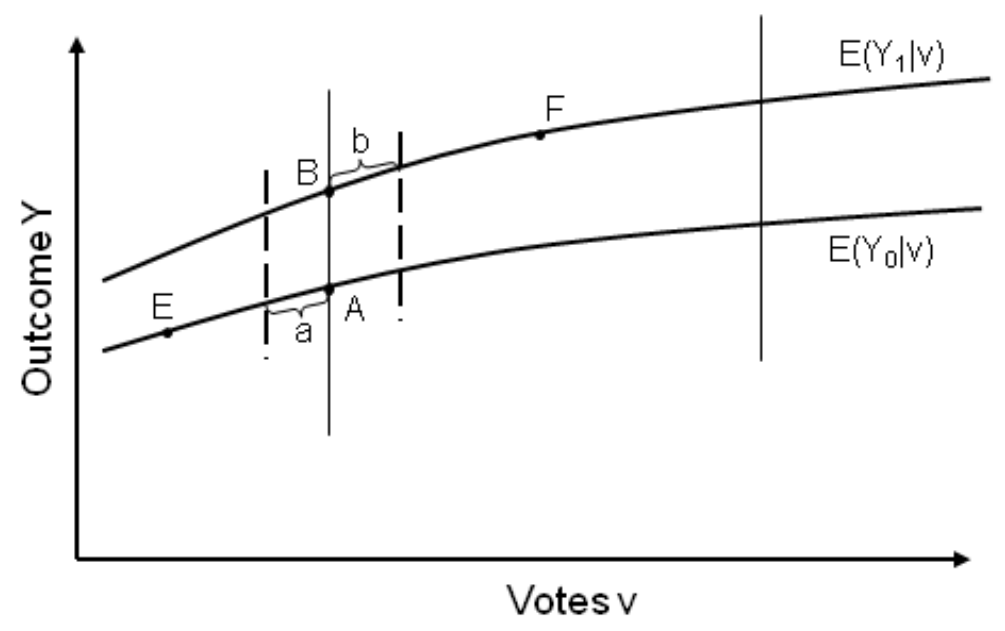

The figure is based on Lee and Lemieux (2009).

Therefore, we have to use the function of the vote vector to account for this distance to a threshold when calculating averages. This distance on the other hand is small, and so is our reliance on the functional form of $f\left(\mathbf{v}_{i}\right)$ : we only need to make sure that the averages on both sides of the thresholds correspond to the points $A$ and $B$ that we are ultimately interested in. In contrast to the specification in equation (7), we do not use $f\left(\mathbf{v}_{i}\right)$ to compare observations in $E$ and $F .^{37}$

Now we turn to the specification of the regression and how we define our instrument. The regression that we estimate is

$$
y_{i}=\alpha+\sum_{j} \beta_{j} p_{i}^{j}+f\left(\mathbf{v}_{i}\right)+\mathbf{X}_{i} \gamma+c_{i}^{j}+\mu_{i}+e_{i},
$$

where $p_{i}^{j}$ is relative voting power of the parties, $f(\cdot)$ is a flexible function of the vote share, $\mathbf{X}_{i}$ is a set of control variables and $\mu_{i}$ is a municipality fixed effect. The variable $c_{i}^{j}$ is defined as follows:

$$
c_{i}^{j}=\left\{\begin{array}{cc}
1 & \text { if voting power was close to a change } \\
0 & \text { otherwise }
\end{array} .\right.
$$

\footnotetext{
${ }^{37}$ In other words, we rely on $f\left(\mathbf{v}_{i}\right)$ only for very short distances, for which even an linear approximation might suffice.
} 
These closeness dummies $c_{i}^{j}$ ensure that our instruments, which we define below, act only as instruments for those observations for which party $j$ was close to gaining or losing voting power, that is, where the instrument is unequal to zero. The observations for which it was not close - where the instrument is zero - will only be used in order to add precision to the estimation of the control function $f\left(\mathbf{v}_{i}\right)$ and increase overall efficiency of the estimates.

Note once more that we have to leave out one party as relative voting power adds up to one. ${ }^{38}$ However, voting power is endogenous so we instrument for voting power using close election outcomes in the following way.

As explained above, we repeatedly perturb the vote vector of each observation, simulate the new seat allocation and calculate the voting power of the parties under this new seat allocation. If one seat switches there are three possible consequences for voting power. First, nothing changes because the seat change was not crucial for whether a coalition is a winning coalition or whether a party is critical. As an example, consider an absolute (super)majority for party A where this party loses one seat but maintains its absolute majority. Second, the voting power of those parties changes that had a seat change. For instance, if party A has 6 and party B has 7 seats, and then, after the perturbation, party A receives 7 and party B 6 seats. For the other parties, nothing changes. With weighted voting power, this scenario is almost impossible, as A and B will not be equally close to a party $\mathrm{C}$ whose voting power will change. And third, the voting power of more than two or even all parties changes. This is far from uncommon: when a seat change leads to different winning coalitions, the voting power of all parties is likely to change, especially with weighted voting power.

To construct our instrument, we first count the number of changes in voting power for each party in a municipality $i$ during the perturbations. However, the size of the jump may also contain useful information that we would like to keep. Therefore, we also calculate the average change in voting power for the times that it did in fact change. Our instrument is then

$$
z_{i}^{j}=\left\{\begin{array}{cc}
\frac{1}{2}\left(p_{i}^{j}-\bar{p}_{i, \text { perturb }}^{j}\right) & \text { if it changes more than } q \% \text { of the time } \\
0 & \text { otherwise. }
\end{array}\right.
$$

where $\bar{p}_{i, \text { perturb }}^{j}$ is the average voting power of party $j$ in municipality $i$ during the

\footnotetext{
${ }^{38} \mathrm{We}$ will come back to the interpretation and potential problems of this adding up constraint in section 4.1 .
} 
perturbations when it in fact changed. The reason for dividing the instrument by two is that we compare observations that had a positive difference to those with a negative difference in the instrument specification. If we take the full difference for each observations, we in fact double the difference. The division by two ensures that the instrument should result in a coefficient of 100 in the first stage.

One might wonder how we can use $z_{i}^{j}$ as an instrument for $p_{i}^{j}$ when the former contains the latter. However, the difference between $p_{i}^{j}$ and $\bar{p}_{i, \text { perturb }}^{j}$ is in fact unrelated to $p_{i}^{j}$ when the election outcome was close, and thus, as good as random: the difference could go either way in varying intensity. We again let $q$ be $\frac{1}{6}$ because this allows for the interpretation that roughly one standard deviation (of our random variable) was necessary to induce this shift.

There are two important assumptions for the validity of our research design: individuals (here: parties or voters) cannot manipulate the vote vector such that a party ends up just above or just below such a voting power threshold. And second, parties cannot manipulate policy in anticipation of a close election.

Election manipulation is (hopefully) impossible in Germany, and voters have no precise information about which side of a seat threshold, let alone a voting power threshold, parties are when making their voting decision (they also neither know the voting behavior of others, nor do they understand the seat allocation functions), so we can safely argue that the first condition is satisfied. ${ }^{39}$ The other issue is more difficult to dismiss a priori. However, we show evidence that there are no party effects for policies enacted before the election. Moreover, we include municipality fixed effects and a dummy for close elections in order to control for some of this variation.

Before we present our results, we should discuss the interpretation of our coefficients. We know that voting power shares always add up to one. This is why we leave out the largest party in Bavaria, the CSU. In a two-party setting, the loss of power for one would be equivalent to power gains for the other. The treatment is then a zero/one variable of which party has the majority. The party effect for one party, leaving out the other obviously, would measure the difference between the two.

We have multiple parties, which could complicate the issue. It is best understood if we shortly review why we are conducting this estimation. Essentially, we want to place parties on a policy line for taxes. The main party will be the fixed point, and we

\footnotetext{
${ }^{39}$ Freier (2011) shows for mayor elections, that are easier to understand and manipulate, that there are no signs of manipulation.
} 
estimate the differences to all other parties. However, we cannot do it separately for each party, but have to do it jointly. That is, each observation gives us the differences between the participating parties. By jointly estimating all existing combinations of parties, we are averaging over all these observations. This is legitimate if parties in fact have fixed positions, regardless of the parties they are running against. ${ }^{40}$ We argue that in the stable political setting of the German states, the party positions are relatively stable such that our approach is justified.

\section{Estimation results and discussion}

The results section is organized in three parts. First, we present and explain our main results for weighted voting power, as well as results for seat shares, for mayors and for other states in the context of our main results. Then, we discuss the broader interpretation of what we find, before turning to the robustness of our main results and assessing the validity of our design.

\subsection{Results}

The left part of table 3 contains the OLS results corresponding to equation 6 . The coefficients are surprisingly small, and mostly insignificant. The results in columns 4-6, based on the IV specification in equation 8, on the other hand show clear effects of party power on policies. More power to the center-left SPD leads to lower taxes across the board. The Greens' power results in higher property taxes, and the pro-market FDP lowers property taxes, although the effects are less significant.

The coefficients measure the effect of a $1 \%$ point gain in voting power share (a real world example is provided below). This means, that a $10 \%$ point gain in voting power share for the Greens results in a 13 point increase in the tax multiplier for property tax B. As we explained in section 2.3, the multipliers are between 150 and 800, so 13 points seems small. However, the change (in absolute values) over an election period is just 11.8 points for the property tax B, with a standard deviation of roughly 23 . For property tax A, the numbers are almost identical $(10.6,23)$; for the trade tax, the average (in absolute values) is 5.8 , with a standard deviation of $15{ }^{41}$

\footnotetext{
${ }^{40}$ Estimating party-pairs separately - which is rare with voting power and the data is limited in practice - is only helpful if we assume that a party has a different position depending on which party they are running against.

${ }^{41}$ The standard deviation if taken for the changes not in absolute values, but in observed changes. Since most municipalities increased the tax, the difference in standard deviations between the two is small, however.
} 
Table 3: OLS and IV results for voting power - average tax rate multipliers

\begin{tabular}{|c|c|c|c|c|c|c|}
\hline & \multicolumn{3}{|c|}{ OLS } & \multicolumn{3}{|c|}{ IV } \\
\hline & \multicolumn{3}{|c|}{ Average Taxes } & \multicolumn{3}{|c|}{ Average Taxes } \\
\hline & Trade Tax & Prop Tax A & Prop Tax B & Trade Tax & Prop Tax A & Prop Tax B \\
\hline & 1 & 2 & 3 & 4 & 5 & 6 \\
\hline \multirow[t]{2}{*}{ SPD } & $0.05^{* * *}$ & -0.04 & -0.06 & $-0.20^{* * *}$ & $-0.27^{* *}$ & $-0.26^{*}$ \\
\hline & $(0.02)$ & $(0.05)$ & $(0.04)$ & $(0.08)$ & $(0.13)$ & $(0.14)$ \\
\hline \multirow[t]{2}{*}{ The Greens } & -0.00 & -0.04 & 0.05 & 0.32 & $1.24^{* *}$ & $1.30^{* *}$ \\
\hline & $(0.12)$ & $(0.29)$ & $(0.26)$ & $(0.33)$ & $(0.56)$ & $(0.59)$ \\
\hline \multirow[t]{2}{*}{ FDP } & 0.04 & $0.74^{*}$ & 0.25 & 0.02 & -0.94 & $-2.91^{*}$ \\
\hline & $(0.18)$ & $(0.44)$ & $(0.39)$ & $(0.89)$ & $(1.52)$ & $(1.59)$ \\
\hline \multirow[t]{2}{*}{ Others } & -0.02 & -0.03 & -0.04 & 0.01 & -0.05 & -0.05 \\
\hline & $(0.01)$ & $(0.03)$ & $(0.03)$ & $(0.05)$ & $(0.09)$ & $(0.09)$ \\
\hline $\mathrm{N}$ & 4030 & 4030 & 4030 & 4030 & 4030 & 4030 \\
\hline
\end{tabular}

Notes: Significance levels: ${ }^{*} p<0.10,{ }^{* *} p<0.05,{ }^{* * *} p<0.01$. Robust standard errors in parentheses. In all regressions the voting power of the CSU is left out and serves as the reference category. The coefficients show the party effect of a one percentage point increase in weighted voting power at the dispense of the CSU. Columns 1-3 refer to the OLS regressions of voting power for the respective parties on the three direct policy instruments (tax rate multipliers). Each regression contains a population control, dummies for each party if it did not receive any votes and state-election dummies. Columns 4-6 refer to the estimates of the IV regressions, in which the weighted voting power measures are instrumented by the shifts in voting power around a threshold in close elections. The instrument is based on 200 perturbations of the vote vector using a variance of $1 \%$ of the vote count. Each regression contains population controls and council size, dummies for each party if it did not receive any votes, state-election dummies, and a polynomial control function that is quadratic in each party's vote share. The specification is estimated using municipality fixed effects. Source: Own calculations.

The first stage of this IV regression is presented in table 6 in the appendix. The second column shows that roughly $7.5 \%$ to $11 \%$ of voting power outcomes were "close" in our definition. This leads to more than 200 observations for the two large parties, CSU and SPD, as well as for others (see column 1). For The Greens and the FDP, the numbers are considerably smaller. Nevertheless, the first stage is very strong for all parties and has the expected coefficient size of roughly $100 .{ }^{42}$

So far, our estimates are vis-a-vis the major party, the center-right CSU. To facilitate the interpretation across all pairs of parties, we turn to table 7 in the appendix. The first column contains all the estimates of table 3 , that is, the effect of voting power gains for the parties at the expense of the CSU. ${ }^{43}$ Regarding the trade tax, for instance, the SPD differs significantly from the parties subsumed in "Others": when Others gain $1 \%$ point in voting power share at the expense of the SPD, the tax

\footnotetext{
${ }^{42}$ Each line represents a separate regression: equation 8 with the actual voting power as the outcome variable. We measure the average jump in voting power (our instrument) between 0 and 1 , and the outcome variable of actual voting power between 0 and 100 .

${ }^{43}$ The general reading of the table is therefore: party in column 1 gains voting power at the expense of the party in the top row.
} 
multiplier increases by 0.21 . The Greens differ from every party regarding property tax B: in the bottom panel, the two entries in comparison to the CSU and SPD, as well as the two entries in column 3 are economically and statistically significant.

As an example of how to interpret a change in voting power for The Greens, consider the municipality of Dietramszell, south of Munich. In a council of 17 (including the mayor), the CSU had 8 seats, the SPD 3 plus the mayor, the Free Voters 4 seats, and The Greens one. The Greens were an important coalition member for the SPD and the Free Voters, as well as for the CSU: in both cases, they were pivotal to the coalition. Our closeness results show that the CSU was close to losing the $8^{\text {th }}$ seat to the SPD. This would have made The Greens entirely powerless: no winning coalition would require The Greens' support. ${ }^{44}$ In our setup with weighted voting power, the Greens would have lost all their $8.2 \%$ points voting power share. In other words, the CSU winning the extra seat made The Greens powerful. Our estimates in table 7 now predict that in this municipality the property tax B multiplier will be 13 points higher. ${ }^{45}$

This increase in the property tax B multiplier translates into a $4.1 \%$ increase in the total property tax liability. ${ }^{46}$ For the trade tax, we assume that the SPD gains $10 \%$ points in voting power share from the CSU. This results in an reduction of the multiplier of two points.

As outlined in section 3.1, the original concept of voting power considers all coalitions as equally likely. Will that change the results? Moreover, our measure of weighted voting power is based on an estimate of party positions by Pappi and Eckstein (1998), and we want to explore how our results change if we take this weighting to an extreme bi-polar party system. ${ }^{47}$ The results are presented in table 8 in the appendix. With the original (unweighted) voting power measure, the results are very similar: the SPD

\footnotetext{
${ }^{44}$ The CSU can no longer form a winning coalition with The Greens, while both the SPD and the Free Voters do not need The Greens anymore. This is comparable to the situation of Luxembourg prior to 1973 in the European Council of Ministers, where it had one vote, but could never affect the outcome of a decision. See Felsenthal and Machover (1998) for details.

${ }^{45}$ The exact calculation is as follows. The Greens and the CSU gain roughly 0.0815 in voting power shares each, whereas the SPD and the Others party lose roughly 0.0815 each (it is a coincidence that the gains and losses are evenly distributed). The best way to understand the change is then to view the SPD as gaining from the CSU, and The Greens gaining from the Others. Then we know that the tax multiplier changes by $-(-0.26)$ points in the first pair, and by $-(-1.35)$ in the second pair, which in total is 1.61 per $1 \%$ point gain in voting power share for the CSU and The Greens. Multiplied by the 8.15 gain yields 13.12 points.

${ }^{46}$ This is the effect evaluated at the mean of the property tax multiplier in Bavaria. For larger multipliers, the effect is smaller in percentage terms.

${ }^{47}$ We consider the parties SPD and The Greens as the left polar, the CSU and the FDP as the right polar, and the Others somewhere in the middle, but closer to the CSU. This gives the Others
} 
still lowers taxes across the board and The Greens increase the property taxes. The bi-polar weighting changes the results only slightly, the major difference being that the pro-market FDP lowers property taxes significantly despite very few observations. This may indicate that the FDP is really restricted in its coalition options to the CSU, as unweighted voting power shows no effect, weighted voting power an effect at the $10 \%$ level, and the extreme weighting shows a significant effect.

Going one step further back, we also consider the effect of seat share changes, using our IV setup. ${ }^{48}$ The results in table 9 in the appendix show a similar trend in most estimates, but more noise. This supports the view that seat shares are a noisy representation of what we actually want to measure: power. The major difference is that the FDP lowers the trade tax multiplier if it has more seats, but not in the case of voting power.

The negative effect of the center-left party SPD on all taxes is surprising. We therefore investigate - in addition to our robustness tests in section 4.3 - whether this SPD effect can be found elsewhere as well. To this end, we use a simple RDD on the mayors in Bavarian municipalities (used by Freier (2011)): the 50\% threshold determines the identity of the mayor, and if one party barely won or lost the election, the outcome is as good as random. ${ }^{49}$ The results are presented in table 4, where the first three columns show the effects of an SPD mayor winning a close race against the opponent that could be of any other party, including the CSU. Columns 4-6 show the results for the CSU candidate barely winning against any opponent. ${ }^{50}$ SPD mayors significantly reduce all three tax rates, and these effects are robust across all specifications. CSU mayors, on the other hand, increase tax rates, although the effects on property tax $\mathrm{B}$ are less significant. There are two key takeaways from these results: First, they lend further support to our main results that more power to the SPD indeed reduces tax rates. Second, they compare well to the results on seat shares in table 9. Since somewhat high power, which we consider reasonable under the assumption of a truly bi-polar party system.

${ }^{48}$ Specifically, we instrument for actual seats with close seat changes that we observe in repeated perturbations. Since we simulate the effect, and may have cases in which one party closely gains a seat, but no party (alone) barely loses a seat, we use the instrumental variable technique as well, even though the results should be similar if we take the seat changes from our simulations directly.

${ }^{49}$ Tests for the validity of this design are given in Freier (2011). In practice, we use all mayor elections that were determined by a very close margin of victory, that is, the votes for the winning candidate were only slightly higher than for the second best candidate. Since the winning mayor has to win more than $50 \%$ (either in the first round against many, or against the runner-up in a second round), the close elections are always a two-candidate race.

${ }^{50}$ Within each block of three columns, the first specification uses close elections only, the second adds the margin of victory as a control function and the third uses the optimal bandwidth estimator of Imbens and Kalyanaraman (2009). 
the mayor is also a member of the council, one more seat in, say, a council of $14+1$ translates into a seat share gain of $6.67 \%$. This in turn translates into a decrease in the trade tax of about 6.2 points, if we take the seat share results as a starting point. ${ }^{51}$

Table 4: RDD results for mayors

\begin{tabular}{|c|c|c|c|c|c|c|}
\hline \multicolumn{7}{|c|}{ First difference in taxes } \\
\hline & \multicolumn{3}{|c|}{ SPD } & \multicolumn{3}{|c|}{$\mathrm{CSU}$} \\
\hline & 1 & 2 & 3 & 4 & 5 & 6 \\
\hline \multirow[b]{2}{*}{ Treatment } & \multicolumn{6}{|c|}{ Panel 1: Trade Tax } \\
\hline & $\begin{array}{c}-8.09^{* *} \\
(3.72)\end{array}$ & $\begin{array}{c}-5.92^{* *} \\
(2.79)\end{array}$ & $\begin{array}{c}-4.96^{* *} \\
(0.04)\end{array}$ & $\begin{array}{l}10.91^{* *} \\
(4.69)\end{array}$ & $\begin{array}{l}5.96^{* * *} \\
(2.06)\end{array}$ & $\begin{array}{l}5.88^{* * *} \\
(2.04)\end{array}$ \\
\hline \multirow[b]{2}{*}{ Treatment } & \multicolumn{6}{|c|}{ Panel 2: Property Tax A } \\
\hline & $\begin{array}{r}-10.39 \\
(6.45)\end{array}$ & $\begin{array}{c}-8.59^{* *} \\
(3.64)\end{array}$ & $\begin{array}{c}-7.52^{* *} \\
(3.38)\end{array}$ & $\begin{array}{c}5.20 \\
(5.06)\end{array}$ & $\begin{array}{l}7.52^{* *} \\
(3.14)\end{array}$ & $\begin{array}{l}8.06^{* * *} \\
(2.87)\end{array}$ \\
\hline \multirow[b]{2}{*}{ Treatment } & \multicolumn{6}{|c|}{ Panel 3: Property Tax B } \\
\hline & $\begin{array}{r}-9.63 \\
(6.73)\end{array}$ & $\begin{array}{c}-8.08^{* *} \\
(3.94)\end{array}$ & $\begin{array}{r}-5.13^{*} \\
(2.81)\end{array}$ & $\begin{array}{c}2.17 \\
(5.11)\end{array}$ & $\begin{array}{c}5.09 \\
(3.35)\end{array}$ & $\begin{array}{c}5.12 \\
(3.13)\end{array}$ \\
\hline $\mathrm{N}$ & 51 & 1192 & 1192 & 76 & 1953 & 1953 \\
\hline \multicolumn{7}{|c|}{$\begin{array}{l}\text { Notes: Significance levels: }{ }^{*} p<0.10,{ }^{* *} p<0.05,{ }^{* * *} p<0.01 \text {. Robust standard errors in } \\
\text { parenthese. This table highlights the results from a mayor RDD for Bavaria from 1996-2008. The } \\
\text { outcome variables are the differences in local tax rates from the end of the election period to the year } \\
\text { before the election period started. Columns } 1-3 \text { refer to a RDD for SPD candidates. A candidate } \\
\text { from the SPD just made it into the mayor office if she received a positive margin of victory over the } \\
\text { best opponent. Treatment is defined as a SPD candidate in office. The RDD compares observations } \\
\text { in which this happened just on the margin against the case of the SPD just losing (and another } \\
\text { party having access to the office). In columns } 4-6 \text {, we show the results of a CSU mayor RDD. For } \\
\text { each outcome and design, we present three different specifications for the RDD. In columns } 1 \text { and } 4 \text {, } \\
\text { we compare 'pure' averages within a limited sample of } 2 \text { percentage points in the margin of victory. } \\
\text { Columns } 2 \text { and } 5 \text {, use the entire sample and specify a } 2 \text { nd order control function in the margin } \\
\text { of victory (flexible on both sides). Finally, columns } 3 \text { and } 6 \text { use the optimal bandwidth estimator } \\
\text { suggested by Imbens and Kalyanaraman (2009). Source: Own calculations. }\end{array}$} \\
\hline
\end{tabular}

As a final set of results, we present the estimation of our main equation 8 in two other states: Hesse in the West and Thuringia in the East. The party identities differ somewhat across states in Germany, so we cannot estimate the effects jointly. Hesse for instance is a typical Western German state with two major parties (CDU and SPD), and two smaller parties (FDP and The Greens). Thuringia on the other hand

\footnotetext{
${ }^{51}$ We could have included close mayor elections in our original setup. However, we are interested in power in the council. Since the mayor is a special member of the council, this would possibly add non-linearities that are beyond the scope of this paper.
} 
is dominated by three parties (CDU, SPD and The Left), while the FDP and The Greens are much less represented. The results are shown in table 5 in the appendix. In Hesse, the only remaining effect is of The Greens on property tax B, but we only have 46 observations compared to 70 in Bavaria. The SPD effect on taxes seems to be a Bavaria-specific outcome. In Thuringia, where the party positions are different from that in Bavaria, the SPD and The Left increase the trade tax. ${ }^{52}$

Table 5: IV results voting power - other states

\begin{tabular}{|c|c|c|c|}
\hline & \multicolumn{3}{|c|}{ Average Taxes } \\
\hline & Trade Tax & Property Tax A & Property Tax B \\
\hline & 1 & 2 & 3 \\
\hline & \multicolumn{3}{|c|}{ Panel 1: Hesse } \\
\hline SPD & $\begin{array}{r}-0.00 \\
(0.18)\end{array}$ & $\begin{array}{c}0.02 \\
(0.44)\end{array}$ & $\begin{array}{c}0.17 \\
(0.39)\end{array}$ \\
\hline The Greens & $\begin{array}{c}0.59 \\
(0.42)\end{array}$ & $\begin{array}{c}0.66 \\
(1.03)\end{array}$ & $\begin{array}{l}1.90^{* *} \\
(0.92)\end{array}$ \\
\hline FDP & $\begin{array}{c}1.09 \\
(0.69)\end{array}$ & $\begin{array}{c}0.45 \\
(1.69)\end{array}$ & $\begin{array}{c}2.37 \\
(1.52)\end{array}$ \\
\hline Others & $\begin{array}{r}-0.04 \\
(0.23)\end{array}$ & $\begin{array}{c}0.14 \\
(0.57)\end{array}$ & $\begin{array}{c}0.29 \\
(0.51)\end{array}$ \\
\hline \multirow[t]{2}{*}{$\mathrm{N}$} & 823 & 823 & 823 \\
\hline & \multicolumn{3}{|c|}{ Panel 2: Thuringia } \\
\hline SPD & $\begin{array}{c}0.26^{*} \\
(0.15)\end{array}$ & $\begin{array}{c}0.20 \\
(0.14)\end{array}$ & $\begin{array}{r}-0.02 \\
(0.15)\end{array}$ \\
\hline The Left & $\begin{array}{c}0.54^{*} \\
(0.30)\end{array}$ & $\begin{array}{c}0.34 \\
(0.29)\end{array}$ & $\begin{array}{c}0.17 \\
(0.30)\end{array}$ \\
\hline Others & $\begin{array}{r}-0.07 \\
(0.11)\end{array}$ & $\begin{array}{r}-0.05 \\
(0.10)\end{array}$ & $\begin{array}{r}-0.07 \\
(0.10)\end{array}$ \\
\hline $\mathrm{N}$ & 1455 & 1455 & 1455 \\
\hline
\end{tabular}

Notes: Significance levels: ${ }^{*} p<0.10,{ }^{* *} p<0.05,{ }^{* * *} p<0.01$. Robust standard errors in parentheses. In this table we repeat the analysis of the effect of voting power on tax decisions for two additional states. Panel 1 and 2 show the estimates for Hessen and Thuringia respectively. We excluded specific parties if there were to few cases in which close elections occurred. The instrument is again based on 200 perturbations of the vote vector using a variance of $1 \%$ of the vote count. Each regression contains population controls and council size, dummies for each party if it did not receive any votes, state-election dummies, and a polynomial control function that is quadratic in each party's vote share. The specification is estimated using municipality fixed effects. Source: Own calculations.

\footnotetext{
${ }^{52}$ The estimations are based on 38 and 25 observations, respectively, which explains the low significance level.
} 


\subsection{Discussion}

What clearly emerges from the preceding exposition is that parties and their respective political power does matter for policy outcomes. In the specific context of Bavara, there are three main results that we discuss in turn. First, the SPD lowers taxes. Second, The Greens increase, and the FDP decreases property taxes. Third, the Others are where we expect them to be: close to the CSU, the major party in Bavaria.

The Others are often so-called "Free Voters" that are reasonably close to the CSU, but without the party affiliation. Therefore, we expect them to have relatively closely aligned policy platforms, and our results confirm this expectation. The Greens raise property taxes - an effect that is confirmed in the state of Hesse and that we expected. For instance, the new Prime Minister of Baden-Wuerttemberg, Winfried Kretschmann (The Greens), directly announced his plans to increase the property transactions tax to finance an extension of kindergartens. ${ }^{53}$ The effect of the FDP to lower property taxes is less stable, but considering the number of observations still reasonably robust. What is interesting about the FDP is that its effect is strongest in the specification where we use our bi-polar voting power measure. This may indicate that the FDP is very limited in its coalition options and only really matters in combination with the CSU.

As indicated above, the negative and very robust (see below) effect of the center-left $\mathrm{SPD}$ on taxes is somewhat surprising. One explanation could be that the SPD may gain voting power, but may not be part of the governing coalition. In other words, the reduction in tax rates could be a CSU policy in response to SPD power gains. We would argue that this still constitutes the effect of SPD power on tax policy, even though the CSU implements the policy as the power has shifted in the SPD's favor. Two of our estimations, however, point in the direction of a genuine SPD policy.

First, an SPD mayor implements similar reduction in tax rates as we would expect from gains in voting power. This is not proof that it is the SPD's own policy as the mayor could be forced by a CSU dominated coalition that acts in response to a voting power gain for the SPD, but it certainly is a strong indication because the mayor is often from one of the larger parties and is often a dominant player in local politics. Second, the extreme bi-polar weighting confirms our results as well. In these estimations, the SPD can only coalesce with The Greens, and to a much lesser extent

\footnotetext{
${ }^{53}$ See FAZ (2011).
} 
with the Others, but not with CSU or FDP. Still, the effects of the SPD remain. ${ }^{54}$

The effects are therefore driven by the SPD itself, and two explanations remain. Either it simply is the policy position of the SPD in Bavaria. ${ }^{55}$ Or the reason is that the SPD has weaker ties to the governments on higher tiers, especially to the state government where the CSU, until recently, held an absolute majority since 1970. This could induce CSU local governments to shy away from tax competition - a constraint that does not hold the SPD back. The trade tax effect supports this argument: not only is it the tax rate that is arguably most affected by tax competition, the effect on the trade tax is also the most robust and most significant in our estimations.

\subsection{Robustness and validity}

We now turn to the last two parts of our results section, the discussion the results' robustness and their validity. First, we test different definitions of the instrument, changes in the degree of closeness, alternative specifications as well as how the results change when we exclude high or low jumps in the voting power. Second, we present various tests for the validity of our instrumental variable approach.

The specification of the instrument can be changed in two opposite ways: either extract more information out of our perturbations than we currently do, or to extract less. We do both here. First, we extract more information by adding the squared instrument to the specification. The reason is that large changes in voting power during the perturbations have a different impact on voting power than small changes: large parties have disproportionately high voting power and therefore relatively high jumps in power at the discontinuities. The squared instrument allows for such a non-linear relationship. The top panel of table 10 shows that the results for this specification are very similar to our main results. Second, we extract less information from our perturbations by using only the direction of the difference, not their size. The lower panel of table 10 contains the estimates from this IV regression. The results do change slightly, but remain robust overall.

Our next robustness check varies the definition of what we consider "close": as our parameter $k$ in the perturbation is moved from $1 \%$ to $2 \%$ or $3 \%$, we expand the sample

\footnotetext{
${ }^{54}$ The effect could, of course, still be driven by the CSU that in response to SPD gains has to bargain harder with the Others that have new coalition options.

${ }^{55}$ There could be a strategic use of debt story behind it: the SPD does not like lower taxes per se, but a more spendthrift government. This would entail lowering taxes now, and increasing the debt level to tie the hands of future governments. However, we find no effect on debt. See Freier and Odendahl (2012) for such an interpretation regarding absolute majorities.
} 
we use for our estimation. The results of this exercise are presented in table 11. The effects of the SPD are in the same range, albeit less significant. The effect of The Greens is only significant in the $3 \%$ sample. For the FDP, the effects can no longer be statistically identified but the point estimates are still sizably negative. Generally, we interpret these tests as confirmation that our results are reasonably robust to a change in the definition of closeness.

Next, we vary the specification of our IV regression; the results are presented in table 12. In panels 1 and 2, we use a linear and 4th order control function of the vote shares of all parties instead of the quadratic specification. In panel 3, we exclude the municipalities fixed effects from the regressions. The results are remarkably robust to those changes in specification.

Finally, we are interested whether our results are being driven by particularly high or low jumps in voting power at the thresholds where they change. For all close voting power outcomes that we identify, we identify the highest absolute value of the voting power jump within this observation. Then we rank the observations according to their highest jump and exclude from the regressions the top and bottom quartiles, respectively. The results are shown in table 13. By leaving out the largest jumps (panel 1) we exclude situations in which, for example, an absolute majority was close to winning or loosing this majority, in which case the jumps in voting power would be large. By excluding the smallest jumps (panel 2) we avoid to give weight to small incremental changes in councils with many parties. The essence of our results for the SPD and The Greens remains stable in both samples. We conclude that our results are not driven by a particular set of observations.

Turning to the validity of our IV regression, we have to show that our assumption that close election outcomes provide us with exogenous variation in voting power is plausibly satisfied. In other words, we should not observe any of the following:

- an effect of instrumented voting power on taxes before the government term in question;

- that past close voting power outcomes can predict future close voting power outcomes, such that politicians can predict it;

- different distributions of vote shares for positive and negative instrument values; or 
- skewed distributions of the instrument for each party: the difference between the actual voting power and the voting power during the perturbations.

We will discuss these aspects in turn.

The lower panel of table 14 shows the IV regression of equation (8) using as the outcome variable the tax rates in the last year before the election. The results for the SPD, The Greens and the FDP are insignificant throughout - as they should be. Moreover, the effects that we find on the tax rates at the end of the government term (see the upper panel) are economically sizable whereas the same effects on the policy measure before the government term are economically negligible (especially for the SPD).

As our second validity check, we estimate a probit model of the probability of a close voting power outcome. ${ }^{56}$ That is, we estimate a regression of a dummy for a close voting power outcome in $t$ on a dummy for a close voting power outcome in $t-1$. The results are presented in table 15 for the SPD (columns 1-3) and The Greens (columns 4-6). In column 1 and 4, we use the dummy for past closeness as the single determinant of current closeness. The effect is significant for the SPD, but the effects are very small and the predictive power (as indicated by $R^{2}$ ) is almost zero. In the next specifications, we include the party's current vote share (columns 2 and 5) as well as a set of dummies for the number of parties in the election (columns 3 and 6). We find that a close voting power outcome is very hard to predict, if at all. Together with the first validity test is this an important argument in favor of our approach.

Finally, we look at two important distributions: the frequency of voting power jumps around the threshold, and the vote share of parties on both sides of the threshold. Both support our research design. The first is shown in figure 2. The jumps in voting power are evenly distributed around zero for each party. ${ }^{57}$ The second set of distributions in figure 3, which shows the frequency of a positive or negative value of the instrument by the vote share of that party, also reveals reasonably well balanced pairs - even though the CDU seems to be getting slightly more positive than negative treatments, contrary to the SPD.

The results of the tests above are reassuring. The randomness in the elections that we consider seems to be a reliable source of exogenous variation in voting power.

\footnotetext{
${ }^{56}$ Note that even if parties could correctly predict that an election is close, it would not automatically invalidate our approach as long as the outcome (more or less voting power) is still determined by chance. However, if parties are unable to predict a close election outcome from past data, this lends support to the external validity of our approach as well.

${ }^{57} \mathrm{We}$ only plot those where voting power did change. There are therefore no observations at zero.
} 


\section{Conclusions}

Political power in a proportional election system has long been a topic of the theoretical literature in political economics and political science. However, the empirical literature has been mostly unsuccessful in reliably identifying a causal effect of power on policy outcomes. This paper attempts to fill that gap. We estimate the causal effects of political power on tax rates in local governments in the German state of Bavaria.

We use voting power as our measure of political power - with the added twist of putting more weight on coalitions that are more likely to form. Close election results provide us with the exogenous variation in voting power. To find these close elections in a multi-party setting, we perturb the voting outcome slightly in repeated simulations. Cases in which the voting power changes often are considered "close". We then use the jumps in voting power during these repeated simulations as an instrument for actual voting power in the council. Our first stage results, plus our validity checks, confirm that this is a suitable instrument for voting power.

The results of our estimation reveal that political power does matter. The Greens and the pro-market FDP are found to affect the main property taxes in opposing directions, much in line with our expectations. What is more, we find voting power to be the better measure than seat shares, especially for small parties. The larger weight on coalitions that are more likely seems to be less important.

The center-left SPD on the other hand is found to lower taxes in Bavaria - albeit not in two other states. This is somewhat surprising, and difficult to explain based on its perceived party position. However, this effect is very robust in Bavaria, and even shows in a simple RDD on Bavarian mayors. We hypothesize that the SPD may simply engage in tax competition to a larger extent than the dominant center-right party CSU that has close ties to higher tiers of government.

\section{References}

Abdulkadiroglu, A., And T. Soenmez (2003): "School Choice: A Mechanism Design Approach," The American Economic Review, 93(3), pp. 729-747.

Ansolabehere, S., J. Snyder, James M., A. B. Strauss, and M. M. Ting (2005): "Voting Weights and Formateur Advantages in the Formation of Coalition Governments," American Journal of Political Science, 49(3), pp. 550-563. 
BAnZhaf, J. F. (1965): "Weighted Voting Doesn't Work: A Mathematical Analysis," Rutgers Law Review, 19, 317-343.

Bilal, S., P. Albuquerque, and M. . Hosli (2001): "The Probability of Coalition Formation: Spatial Voting Power Indices," Paper to be presented at the ECSA Seventh Biennial International Conference, Maddison, Wisconsin, USA.

Black, D., J. Galdo, And J. Smith (2005): "Evaluating the Regression Discontinuity Design Using Experimental Data," unpublished manuscript, Syracuse University.

Bundesbank (2007): "Zur Entwicklung der Gemeindefinanzen seit dem Jahr 2000," Monatsbericht.

Bundesfinanzministerium (2012): "Die Steuereinnahmen der Gemeinden, Stand Januar 2012," Brochure.

Bundeszentralamt fuer Steuern (2012): "Trade Tax (Gewerbesteuer)," Internet document, www.steuerliches-info-center.de.

Caughey, D. M., and J. S. Sekhon (2011): "Regression-Discontinuity Designs and Popular Elections: Implications of Pro-Incumbent Bias in Close U.S. House Races," Working Paper.

FAZ (2011): "Wir stehen vor einer neuen Gründerzeit," Frankfurter Allgemeine Zeitung, 25.05.2011.

Felsenthal, D. S., And M. Machover (1998): The Measurement of Voting Power. Edward Elgar Publishing, Cheltenham.

Ferreira, F., And J. Gyourko (2009): "Do Political Parties Matter? Evidence from U.S. Cities," Quarterly Journal of Economics, 124(1), 399-422.

Fiva, J. H., O. Folke, and R. J. Sorensen (2011): "Political Representation and Fiscal Policy: A Casual or Causal Relationship?," mimeo.

Folke, O. (2010): "Shades of Brown and Green: Party Effects in Proportional Election Systems," Working Paper, IIES.

FreIER, R. (2011): "Incumbency as the major advantage - The scopes and determinants of the electoral advantage for incumbent mayors," available as DIW working paper soon. 
Freier, R., And C. Odendahl (2012): "Do absolute majorities spend less? Evidence from Germany," mimeo.

Grimmer, J., E. Hersh, B. Feinstein, and D. Carpenter (2011): "Are Close Elections Random?," Working Paper.

Hahn, J., P. Todd, and W. Van der KlaAuw (2001): "Identification and Estimation of Treatment Effects with a Regression-Discontinuity Design," Econometrica, 69(1), 201209.

Imbens, G. W., and K. Kalyanaraman (2009): "Optimal Bandwidth Choice for the Regression Discontinuity Estimator," IZA Discussion Papers 3995, Institute for the Study of Labor (IZA).

Lee, D. S., And T. Lemieux (2009): "Regression Discontinuity Designs in Economics," NBER Working Paper No. 14723.

Lee, D. S., E. Moretti, And M. Butler (2004): "Do Voters Affect or Elect Policies? Evidence from the U.S. House," Quarterly Journal of Economics, 119(3), $807-859$.

Pappi, F. U., And G. Eckstein (1998): "Voters' Party Preferences in Multiparty Systems and Their Coalitional and Spatial Implications: Germany after Unification," Public Choice, 97(3), 229-55.

Penrose, L. S. (1946): "The Elementary Statistics of Majority Voting," Journal of the Royal Statistical Society, 109(1), 53-57.

Persson, T., and G. Tabellini (2002): Political Economics: Explaining Economic Policy. The MIT Press.

Pettersson-Lidbom, P. (2008): "Do Parties Matter for Economic Outcomes? A Regression-Discontinuity Approach," Journal of European Economic Association, 6(5), 1037-1056.

Riker, W. H. (1982): "The Two-Party System and Duverger's Law: An Essay on the History of Political Science," The American Political Science Review, 76(4), pp. $753-766$.

Snyder, James M., J., M. M. Ting, and S. Ansolabehere (2005): "Legislative Bargaining under Weighted Voting," The American Economic Review, 95(4), pp. 981-1004. 


\section{A Appendix}

\section{A.1 Estimation specification for seat shares}

For seat shares as the variable of interest, the empirical strategy is related to the one presented in section 3.3 , but slightly different. ${ }^{58}$ For the close seats in a council of size $Z_{i}$ we will define a treatment variable $t_{i}^{j}$. This treatment variable takes on the value $+\frac{1}{2} / Z_{i}$ if the close seat was just above a threshold, that is, the party was close to losing this seat, and $-\frac{1}{2} / Z_{i}$ in the opposite case. We call the two values positive and negative treatment respectively:

$$
t_{i}^{j}=\left\{\begin{array}{cc}
+\frac{1}{2} / Z_{i} & \text { for positive treatment } \\
-\frac{1}{2} / Z_{i} & \text { for negative treatment } \\
0 & \text { otherwise }
\end{array}\right.
$$

The values ensure that the difference between gaining and losing a seat is one divided by the council size, that is, the difference between positive and negative treatment is measured in terms of seat shares. This facilitates the interpretation of the coefficients.

We could use these variables in a regression of the outcome $y_{i}$ without instrumenting. If we had just one forcing variable and could get arbitrarily close to the thresholds, the difference between negative and positive treatment observations would be equal to one seat and we could just use it in a regression. ${ }^{59}$ However, the forcing variable is in fact a vector and we cannot get arbitrarily close to the thresholds. Therefore, our treatment variable is only approximately correct and we therefore use an instrumental variable strategy, where we instrument for seat shares with our treatment variable. This ensures that our regression coefficients represent the effect we want to estimate: the effect of $1 \%$ additional seat share.

The regression that we are going to estimate therefore takes the following form:

$$
y_{i}=\alpha+\sum_{j} \beta_{j} s_{i}^{j}+f\left(\mathbf{v}_{i}\right)+\mathbf{X}_{i} \gamma+c_{i}^{j}+\mu_{i}+e_{i},
$$

where $f(\cdot)$ is the flexible function of the vote share, $\mathbf{X}_{i}$ is a set of control variables, $c_{i}^{j}$ is the closeness dummy as in the voting power specification and $\mu_{i}$ is a municipality fixed effect. We instrument for the seat shares $s_{i}^{j}$ with our treatment variables $t_{i}^{j}$. The set of control variables include population of the municipality and dummies for each state-wide municipal election.

\footnotetext{
${ }^{58}$ The specification is closely related to the one in Folke (2010).

${ }^{59} \mathrm{We}$ would correct for different council sizes, of course.
} 
Note again that we leave out one party, the CDU, in all specifications as the seat shares add up to one by definition. The CDU is the biggest party and takes part in almost all of the elections in the western states, and most of the elections in Thuringia. The interpretation of the $\beta$ 's is therefore: the effect of an increase in party $j$ 's seat share by $1 \%$ at the expense of the CDU on the policy outcome. ${ }^{60}$

\section{A.2 Tables and figures}

Table 6: First stage results and \# of close elections

\begin{tabular}{|c|c|c|c|c|}
\hline & \multicolumn{2}{|c|}{ \# of close elections } & \multicolumn{2}{|c|}{ First Stage coef } \\
\hline & Absolute & As share & Own coeff & F-Test \\
\hline & 1 & 2 & 3 & 4 \\
\hline $\mathrm{CDU}$ & 268 & $7.99 \%$ & $\begin{array}{c}105.05^{* * *} \\
(0.000)\end{array}$ & $\begin{array}{c}37.33^{\text {***}} \\
(0.000)\end{array}$ \\
\hline SPD & 234 & $8.94 \%$ & $\begin{array}{c}105.43^{* * *} \\
(0.000)\end{array}$ & $\begin{array}{c}48.06^{* * *} \\
(0.000)\end{array}$ \\
\hline The Greens & 70 & $10.80 \%$ & $\begin{array}{l}93.72^{* * *} \\
(0.000)\end{array}$ & $\begin{array}{c}64.26^{* * *} \\
(0.000)\end{array}$ \\
\hline FDP & 25 & $8.42 \%$ & $\begin{array}{l}93.81^{* * *} \\
(0.000)\end{array}$ & $\begin{array}{c}69.55^{\text {*** }} \\
(0.000)\end{array}$ \\
\hline Others & 281 & $7.42 \%$ & $\begin{array}{c}89.65^{* * *} \\
(0.000)\end{array}$ & $\begin{array}{c}31.23^{* * *} \\
(0.000)\end{array}$ \\
\hline
\end{tabular}

Notes: Significance levels: ${ }^{*} p<0.10,{ }^{* *} p<0.05,{ }^{* * *} p<0.01$. P-values in parentheses. Columns 1 and 2 present the number of close elections in which voting power was at the margin in absolute number and as a share of those observations in which the party participated. Columns 3 and 4 show the results of the first stage regressions for each party's representation measure. Column 3 presents the respective values on each coefficient (each from a different regression). F-Stat values are highlighted in column 4 and refer to the FStatistic for the join test of all instruments in each of the first stages. Included controls are the 2 nd order vote share function including squared vote shares of all parties, population, dummies if the parties received no votes, the $c_{i}^{j}$ dummies for each party if it was close, as well as state-election dummies. Source: Own calculations.

\footnotetext{
${ }^{60}$ We measure seat shares from 0 to 100 in order to allow for this interpretation.
} 
Table 7: IV results voting power - party by party

\begin{tabular}{|c|c|c|c|c|c|}
\hline & \multicolumn{5}{|c|}{ Average Taxes } \\
\hline & $\mathrm{CSU}$ & SPD & Greens & FDP & Others \\
\hline & 1 & 2 & 3 & 4 & 5 \\
\hline & \multicolumn{5}{|c|}{ Panel 1: Trade tax } \\
\hline SPD & $\begin{array}{c}-0.20^{* * *} \\
(0.008)\end{array}$ & & & & \\
\hline The Greens & $\begin{array}{l}0.32 \\
(0.335)\end{array}$ & $\begin{array}{l}0.52 \\
(0.133)\end{array}$ & & & \\
\hline FDP & $\begin{array}{l}0.02 \\
(0.983)\end{array}$ & $\begin{array}{l}0.22 \\
(0.805)\end{array}$ & $\begin{array}{c}-0.30 \\
(0.779)\end{array}$ & & \\
\hline \multirow[t]{2}{*}{ Others } & $\begin{array}{c}0.01 \\
(0.866)\end{array}$ & $\begin{array}{r}0.21^{* *} \\
(0.016)\end{array}$ & $\begin{array}{l}-0.31 \\
(0.355)\end{array}$ & $\begin{array}{l}-0.01 \\
(0.991)\end{array}$ & \\
\hline & \multicolumn{5}{|c|}{ Panel 2: Property Tax A } \\
\hline $\mathrm{SPD}$ & $\begin{array}{r}-0.27^{* *} \\
(0.042)\end{array}$ & & & & \\
\hline The Greens & $\begin{array}{l}1.24^{* *} \\
(0.027)\end{array}$ & $\begin{array}{c}1.51^{* *} \\
(0.011)\end{array}$ & & & \\
\hline FDP & $\begin{array}{c}-0.94 \\
(0.538)\end{array}$ & $\begin{array}{c}-0.67 \\
(0.663)\end{array}$ & $\begin{array}{c}-2.18 \\
(0.228)\end{array}$ & & \\
\hline \multirow[t]{2}{*}{ Others } & $\begin{array}{c}-0.05 \\
(0.597) \\
\end{array}$ & $\begin{array}{c}0.22 \\
(0.139)\end{array}$ & $\begin{array}{r}-1.29^{* *} \\
(0.024)\end{array}$ & $\begin{array}{l}0.89 \\
(0.557)\end{array}$ & \\
\hline & \multicolumn{5}{|c|}{ Panel 3: Property Tax B } \\
\hline SPD & $\begin{array}{c}-0.26^{*} \\
(0.057)\end{array}$ & & & & \\
\hline The Greens & $\begin{array}{c}1.30^{* *} \\
(0.027)\end{array}$ & $\begin{array}{l}1.56^{* * *} \\
(0.012)\end{array}$ & & & \\
\hline FDP & $\begin{array}{c}-2.91^{*} \\
(0.068)\end{array}$ & $\begin{array}{l}-2.65 \\
(0.010)\end{array}$ & $\begin{array}{r}-4.21^{* *} \\
(0.026)\end{array}$ & & \\
\hline Others & $\begin{array}{c}-0.05 \\
(0.598)\end{array}$ & $\begin{array}{l}0.21 \\
(0.173)\end{array}$ & $\begin{array}{r}-1.35^{* *} \\
(0.024)\end{array}$ & $\begin{array}{c}2.86^{*} \\
(0.072)\end{array}$ & \\
\hline
\end{tabular}

Notes: Significance levels: ${ }^{*} p<0.10,{ }^{* *} p<0.05,{ }^{* * *} p<0.01$. P-Values in parentheses. The table shows the pairwise comparison of party effects that is implied by the estimation results given in table 3 . The first column gives the party effects of a percentage point increase in voting power for the respective party (given on the left) against the conservative CSU. In columns 2-4, we show how a shift of voting power between other parties will affect tax policy. Panel 1-3 highlight the results for each of the three local tax rates respectively. Source: Own calculations. 
Table 8: IV results (un)-weighted voting power

\begin{tabular}{|c|c|c|c|}
\hline & \multicolumn{3}{|c|}{ Average Taxes } \\
\hline & Trade Tax & Property Tax A & Property Tax B \\
\hline & 1 & 2 & 3 \\
\hline & \multicolumn{3}{|c|}{ Panel 1: Unweighted } \\
\hline SPD & $\begin{array}{c}-0.21^{* * *} \\
(0.08)\end{array}$ & $\begin{array}{c}-0.28^{* *} \\
(0.13)\end{array}$ & $\begin{array}{c}-0.27^{* *} \\
(0.14)\end{array}$ \\
\hline The Greens & $\begin{array}{c}0.37 \\
(0.32)\end{array}$ & $\begin{array}{l}1.22^{* *} \\
(0.54)\end{array}$ & $\begin{array}{c}1.29^{* *} \\
(0.56)\end{array}$ \\
\hline FDP & $\begin{array}{c}0.12 \\
(0.81)\end{array}$ & $\begin{array}{r}-0.37 \\
(1.39)\end{array}$ & $\begin{array}{c}-2.10 \\
(1.44)\end{array}$ \\
\hline \multirow[t]{2}{*}{ Others } & $\begin{array}{c}-0.00 \\
(0.05)\end{array}$ & $\begin{array}{c}-0.05 \\
(0.09)\end{array}$ & $\begin{array}{c}-0.06 \\
(0.09)\end{array}$ \\
\hline & \multicolumn{3}{|c|}{ Panel 2: Weighted by distance in one dimensional policy space (extreme) } \\
\hline $\mathrm{SPD}$ & $\begin{array}{c}-0.22^{\text {*** }} \\
(0.08)\end{array}$ & $\begin{array}{c}-0.29^{* *} \\
(0.14)\end{array}$ & $\begin{array}{r}-0.29^{*} \\
(0.15)\end{array}$ \\
\hline The Greens & $\begin{array}{c}0.64 \\
(0.58)\end{array}$ & $\begin{array}{r}1.70^{*} \\
(1.03)\end{array}$ & $\begin{array}{c}2.07^{*} \\
(1.11)\end{array}$ \\
\hline FDP & $\begin{array}{r}-0.88 \\
(0.79)\end{array}$ & $\begin{array}{c}-1.77 \\
(1.39)\end{array}$ & $\begin{array}{c}-3.01^{* *} \\
(1.50)\end{array}$ \\
\hline Others & $\begin{array}{c}-0.02 \\
(0.05)\end{array}$ & $\begin{array}{r}-0.08 \\
(0.09)\end{array}$ & $\begin{array}{c}-0.10 \\
(0.10)\end{array}$ \\
\hline
\end{tabular}

Notes: Significance levels: ${ }^{*} p<0.10,{ }^{* *} p<0.05,{ }^{* * *} p<0.01$. Robust standard errors in parentheses. In this table we use unweighted and extremely weighted voting power in coalitions with an approximated party distance. Panel 1 shows the results on tax making when we use no weighting and give equal weight to each coalition. In panel 2, we use a one dimensional policy space for weighting, however, we assume extreme positions in which SPD and The Greens may form coalitions with each other and independent parties, but not with FDP and CDU. The instrument is again based on 200 perturbations of the vote vector using a variance of $1 \%$ of the vote count. Each regression contains population controls and council size, dummies for each party if it did not receive any votes, state-election dummies, and a polynomial control function that is quadratic in each party's vote share. The specification is estimated using municipality fixed effects. Source: Own calculations. 
Table 9: OLS and IV results for seat shares - average tax rate multipliers

\begin{tabular}{|c|c|c|c|c|c|c|}
\hline & \multicolumn{3}{|c|}{ OLS } & \multicolumn{3}{|c|}{ IV } \\
\hline & \multicolumn{3}{|c|}{ Average Taxes } & \multicolumn{3}{|c|}{ Average Taxes } \\
\hline & Trade Tax & Property A & Property B & Trade Tax & Property A & Property B \\
\hline & 1 & 2 & 3 & 4 & 5 & 6 \\
\hline \multirow[t]{2}{*}{ SPD } & $0.09^{* *}$ & $-0.28^{* * *}$ & $-0.41^{* * *}$ & $-0.93^{* * *}$ & $-1.37^{* *}$ & $-1.47^{* *}$ \\
\hline & $(0.04)$ & $(0.10)$ & $(0.09)$ & $(0.35)$ & $(0.58)$ & $(0.59)$ \\
\hline \multirow[t]{2}{*}{ The Greens } & -0.11 & -0.21 & -0.11 & -0.79 & $2.83^{*}$ & 2.36 \\
\hline & $(0.19)$ & $(0.47)$ & $(0.41)$ & $(1.02)$ & $(1.69)$ & $(1.74)$ \\
\hline \multirow[t]{2}{*}{ FDP } & -0.08 & 0.76 & -0.07 & $-5.66^{* *}$ & 1.23 & -3.27 \\
\hline & $(0.22)$ & $(0.55)$ & $(0.48)$ & $(2.20)$ & $(3.64)$ & $(3.75)$ \\
\hline \multirow[t]{2}{*}{ Others } & -0.03 & $-0.16^{* *}$ & $-0.17^{* * *}$ & -0.17 & $-0.70^{*}$ & -0.55 \\
\hline & $(0.03)$ & $(0.07)$ & $(0.06)$ & $(0.26)$ & $(0.42)$ & $(0.44)$ \\
\hline $\mathrm{N}$ & 4112 & 4112 & 4112 & 4112 & 4112 & 4112 \\
\hline
\end{tabular}

Notes: Significance levels: ${ }^{*} p<0.10,{ }^{* *} p<0.05,{ }^{* * *} p<0.01$. Robust standard errors in parentheses. Columns 1-3 refer to the OLS regressions of seat shares for the respective parties on the three direct policy instruments (tax rate multipliers). The design of the table is similar to table 3. Each regression contains a population control, dummies for each party if it did not receive any votes and state-election dummies. Columns 4-6 refer to the estimates of the IV regressions, in which seat shares are instrumented by the seat share shifts around a threshold in close elections. The instrument is based on 1000 perturbations of the vote vector using a variance of $1 \%$ of the vote count. Each regression contains population controls and council size, dummies for each party if it did not receive any votes, state-election dummies, and a polynomial control function that is quadratic in each party's vote share. The specification is estimated using municipality fixed effects. Source: Own calculations. 
Table 10: IV results voting power - varying the instrument

\begin{tabular}{|c|c|c|c|}
\hline & \multicolumn{3}{|c|}{ Average Taxes } \\
\hline & Trade Tax & Property Tax A & Property Tax B \\
\hline & 1 & 2 & 3 \\
\hline & \multicolumn{3}{|c|}{ Panel 1: Adding the squared jumps in vp } \\
\hline SPD & $\begin{array}{c}-0.21^{* * *} \\
(0.08)\end{array}$ & $\begin{array}{c}-0.28^{* *} \\
(0.13)\end{array}$ & $\begin{array}{c}-0.28^{* *} \\
(0.14)\end{array}$ \\
\hline The Greens & $\begin{array}{c}0.37 \\
(0.33)\end{array}$ & $\begin{array}{c}1.32^{* *} \\
(0.57)\end{array}$ & $\begin{array}{c}1.42^{* *} \\
(0.59)\end{array}$ \\
\hline FDP & $\begin{array}{c}0.05 \\
(0.89)\end{array}$ & $\begin{array}{c}-0.90 \\
(1.53)\end{array}$ & $\begin{array}{r}-2.85^{*} \\
(1.60)\end{array}$ \\
\hline \multirow[t]{2}{*}{ Others } & $\begin{array}{r}-0.00 \\
(0.05)\end{array}$ & $\begin{array}{r}-0.06 \\
(0.09)\end{array}$ & $\begin{array}{r}-0.07 \\
(0.09)\end{array}$ \\
\hline & \multicolumn{3}{|c|}{ Panel 2: Using only 1/ -1 information } \\
\hline SPD & $\begin{array}{c}-0.34^{* * *} \\
(0.13)\end{array}$ & $\begin{array}{r}-0.41^{*} \\
(0.22)\end{array}$ & $\begin{array}{r}-0.40^{*} \\
(0.22)\end{array}$ \\
\hline The Greens & $\begin{array}{c}0.08 \\
(0.36)\end{array}$ & $\begin{array}{c}0.40 \\
(0.60)\end{array}$ & $\begin{array}{c}0.45 \\
(0.63)\end{array}$ \\
\hline FDP & $\begin{array}{c}0.27 \\
(1.33)\end{array}$ & $\begin{array}{c}-0.91 \\
(2.21)\end{array}$ & $\begin{array}{c}-3.02 \\
(2.31)\end{array}$ \\
\hline Others & $\begin{array}{c}0.09 \\
(0.09)\end{array}$ & $\begin{array}{c}0.10 \\
(0.15)\end{array}$ & $\begin{array}{c}0.12 \\
(0.16)\end{array}$ \\
\hline
\end{tabular}

Notes: Significance levels: ${ }^{*} p<0.10,{ }^{* *} p<0.05,{ }^{* * *} p<0.01$. Robust standard errors in parentheses. The table shows a robustness test of the weighted voting power analysis on tax rate multipliers in which we have altered the instrument that we use. In panel 1, we additionally use the squares of the jump in the first stage regression. In panel 2 , we limit the information of the instrument to the sign of the jump and use indicator variable for a negative or a positive jump. The instrument is again based on 200 perturbations of the vote vector using a variance of $1 \%$ of the vote count. Each regression contains population controls and council size, dummies for each party if it did not receive any votes, state-election dummies, and a polynomial control function that is quadratic in each party's vote share. The specification is estimated using municipality fixed effects. The number of observations in each regression is 4030. Source: Own calculations. 
Table 11: IV results voting power - alternative close samples

\begin{tabular}{|c|c|c|c|}
\hline & \multicolumn{3}{|c|}{ Average Taxes } \\
\hline & Trade Tax & Property Tax A & Property Tax B \\
\hline & 1 & 2 & 3 \\
\hline & \multicolumn{3}{|c|}{ Panel 1: $3 \%$ closeness definition } \\
\hline SPD & $\begin{array}{r}-0.01 \\
(0.05)\end{array}$ & $\begin{array}{r}-0.15^{*} \\
(0.09)\end{array}$ & $\begin{array}{r}-0.10 \\
(0.09)\end{array}$ \\
\hline The Greens & $\begin{array}{c}0.10 \\
(0.18)\end{array}$ & $\begin{array}{c}0.75^{* *} \\
(0.30)\end{array}$ & $\begin{array}{c}0.63^{* *} \\
(0.31)\end{array}$ \\
\hline FDP & $\begin{array}{c}0.28 \\
(0.48)\end{array}$ & $\begin{array}{r}-0.07 \\
(0.81)\end{array}$ & $\begin{array}{r}-1.13 \\
(0.84)\end{array}$ \\
\hline \multirow[t]{2}{*}{ Others } & $\begin{array}{c}0.01 \\
(0.04)\end{array}$ & $\begin{array}{c}-0.06 \\
(0.07)\end{array}$ & $\begin{array}{r}-0.07 \\
(0.07)\end{array}$ \\
\hline & \multicolumn{3}{|c|}{ Panel 2: $2 \%$ closeness definition } \\
\hline SPD & $\begin{array}{r}-0.10^{*} \\
(0.06)\end{array}$ & $\begin{array}{r}-0.18^{*} \\
(0.10)\end{array}$ & $\begin{array}{r}-0.16 \\
(0.10)\end{array}$ \\
\hline The Greens & $\begin{array}{r}-0.06 \\
(0.23)\end{array}$ & $\begin{array}{c}0.50 \\
(0.39)\end{array}$ & $\begin{array}{c}0.42 \\
(0.41)\end{array}$ \\
\hline FDP & $\begin{array}{c}1.60^{* *} \\
(0.80)\end{array}$ & $\begin{array}{c}-0.01 \\
(1.35)\end{array}$ & $\begin{array}{r}-0.98 \\
(1.40)\end{array}$ \\
\hline Others & $\begin{array}{c}0.04 \\
(0.04)\end{array}$ & $\begin{array}{c}-0.05 \\
(0.07)\end{array}$ & $\begin{array}{c}-0.06 \\
(0.08)\end{array}$ \\
\hline
\end{tabular}

Notes: Significance levels: ${ }^{*} p<0.10,{ }^{* *} p<0.05,{ }^{* * *} p<0.01$. Robust standard errors in parentheses. The table shows a robustness test of the weighted voting power analysis on tax rate multipliers in which we use different definitions of closeness in the perturbation used to calculate close elections. In the upper panel 1 , we perturb the vote vector using a variance of $3 \%$ of the vote count. In panel 2, we use choose a band for the variance of $2 \%$ of the vote count. Each regression contains population controls and council size, dummies for each party if it did not receive any votes, state-election dummies, and a polynomial control function that is quadratic in each party's vote share. The specification is estimated using municipality fixed effects. The number of observations in each regression is 4030 . The number of close elections in those specifications is as follows: CDU - 699 (3\% sample) and 501 (2\% sample), SPD - 630 and 450, The Greens - 210 and 142, FDP - 82 and 51, Others - 766 and 541. Source: Own calculations. 
Table 12: Robustness: IV results voting power - alternative specifications

\begin{tabular}{|c|c|c|c|}
\hline & \multicolumn{3}{|c|}{ Local Taxes } \\
\hline & Trade Tax & Property Tax A & Property Tax B \\
\hline & 1 & 2 & 3 \\
\hline & \multicolumn{3}{|c|}{ Panel 1: Linear control function } \\
\hline $\mathrm{SPD}$ & $\begin{array}{c}-0.20^{* * *} \\
(0.08)\end{array}$ & $\begin{array}{c}-0.27^{* *} \\
(0.13)\end{array}$ & $\begin{array}{c}-0.27^{* *} \\
(0.14)\end{array}$ \\
\hline The Greens & $\begin{array}{c}0.37 \\
(0.33)\end{array}$ & $\begin{array}{l}1.30^{* *} \\
(0.57)\end{array}$ & $\begin{array}{l}1.39^{* *} \\
(0.59)\end{array}$ \\
\hline FDP & $\begin{array}{c}0.04 \\
(0.89)\end{array}$ & $\begin{array}{c}-0.79 \\
(1.53)\end{array}$ & $\begin{array}{r}-2.77^{*} \\
(1.60)\end{array}$ \\
\hline \multirow[t]{2}{*}{ Others } & $\begin{array}{c}0.00 \\
(0.05)\end{array}$ & $\begin{array}{r}-0.06 \\
(0.09)\end{array}$ & $\begin{array}{r}-0.07 \\
(0.09)\end{array}$ \\
\hline & \multicolumn{3}{|c|}{ Panel 2: 4th order control function } \\
\hline SPD & $\begin{array}{c}-0.21^{* * *} \\
(0.08)\end{array}$ & $\begin{array}{c}-0.28^{* *} \\
(0.14)\end{array}$ & $\begin{array}{r}-0.28^{*} \\
(0.14)\end{array}$ \\
\hline The Greens & $\begin{array}{c}0.36 \\
(0.33)\end{array}$ & $\begin{array}{l}1.36^{* *} \\
(0.56)\end{array}$ & $\begin{array}{c}1.44^{* *} \\
(0.59)\end{array}$ \\
\hline FDP & $\begin{array}{c}0.13 \\
(0.92)\end{array}$ & $\begin{array}{c}-1.04 \\
(1.59)\end{array}$ & $\begin{array}{r}-3.06^{*} \\
(1.66)\end{array}$ \\
\hline \multirow[t]{2}{*}{ Others } & $\begin{array}{c}0.00 \\
(0.05)\end{array}$ & $\begin{array}{r}-0.07 \\
(0.09)\end{array}$ & $\begin{array}{r}-0.08 \\
(0.10)\end{array}$ \\
\hline & \multicolumn{3}{|c|}{ Panel 3: without fixed effects } \\
\hline $\mathrm{SPD}$ & $\begin{array}{c}-0.19^{* * *} \\
(0.07)\end{array}$ & $\begin{array}{c}-0.27^{* *} \\
(0.13)\end{array}$ & $\begin{array}{c}-0.29^{* *} \\
(0.13)\end{array}$ \\
\hline The Greens & $\begin{array}{c}0.15 \\
(0.31)\end{array}$ & $\begin{array}{l}1.17^{* *} \\
(0.55)\end{array}$ & $\begin{array}{c}1.11^{* *} \\
(0.55)\end{array}$ \\
\hline FDP & $\begin{array}{c}0.23 \\
(0.73)\end{array}$ & $\begin{array}{c}-0.51 \\
(1.36)\end{array}$ & $\begin{array}{r}-1.69 \\
(1.36)\end{array}$ \\
\hline Others & $\begin{array}{c}0.01 \\
(0.05)\end{array}$ & $\begin{array}{r}-0.08 \\
(0.09)\end{array}$ & $\begin{array}{c}-0.10 \\
(0.09)\end{array}$ \\
\hline
\end{tabular}

Notes: Significance levels: ${ }^{*} p<0.10,{ }^{* *} p<0.05,{ }^{* * *} p<0.01$. Robust standard errors in parentheses. The table shows the estimates of IV regressions for weighted voting power, in which we have varied the precise specification. In panel 1 and 2, we use a linear and 4 th order control function respectively instead of a quadratic specification. In panel 3, we estimate the IV estimation without municipal fixed effects. The instrument is based on 200 perturbations of the vote vector using a variance of $1 \%$ of the vote count. Each regression contains population controls and council size, dummies for each party if it did not receive any votes, state-election dummies, and a polynomial control function. In panel 3 that control function is quadratic in each party's vote share. The specification is estimated using municipality fixed effects (except in panel 3). The number of observations in each regression is 4030. Source: Own calculations. 
Table 13: Robustness: excluding top and bottom quartiles

\begin{tabular}{|c|c|c|c|}
\hline & \multicolumn{3}{|c|}{ Local Taxes } \\
\hline & Trade Tax & Property Tax A & Property Tax B \\
\hline & 1 & 2 & 3 \\
\hline & \multicolumn{3}{|c|}{ Panel 1: Exclude top quartile } \\
\hline SPD & $\begin{array}{r}-0.41^{*} \\
(0.21)\end{array}$ & $\begin{array}{r}-0.73^{*} \\
(0.39)\end{array}$ & $\begin{array}{r}-0.41 \\
(0.39)\end{array}$ \\
\hline The Greens & $\begin{array}{c}0.10 \\
(0.34)\end{array}$ & $\begin{array}{c}1.18^{*} \\
(0.63)\end{array}$ & $\begin{array}{l}1.35^{* *} \\
(0.63)\end{array}$ \\
\hline FDP & $\begin{array}{c}0.31 \\
(0.57)\end{array}$ & $\begin{array}{c}0.43 \\
(1.08)\end{array}$ & $\begin{array}{c}0.34 \\
(1.07)\end{array}$ \\
\hline \multirow[t]{2}{*}{ Others } & $\begin{array}{c}0.07 \\
(0.17)\end{array}$ & $\begin{array}{c}0.13 \\
(0.32)\end{array}$ & $\begin{array}{c}0.37 \\
(0.32)\end{array}$ \\
\hline & \multicolumn{3}{|c|}{ Panel 2: Exclude bottom quartile } \\
\hline SPD & $\begin{array}{c}-0.20^{* * *} \\
(0.07)\end{array}$ & $\begin{array}{c}-0.28^{* *} \\
(0.13)\end{array}$ & $\begin{array}{c}-0.31^{* *} \\
(0.13)\end{array}$ \\
\hline The Greens & $\begin{array}{c}0.24 \\
(0.32)\end{array}$ & $\begin{array}{l}1.46^{* *} \\
(0.57)\end{array}$ & $\begin{array}{c}1.38^{* *} \\
(0.58)\end{array}$ \\
\hline FDP & $\begin{array}{c}0.32 \\
(0.75)\end{array}$ & $\begin{array}{r}-0.75 \\
(1.39)\end{array}$ & $\begin{array}{r}-1.91 \\
(1.39)\end{array}$ \\
\hline Others & $\begin{array}{c}0.01 \\
(0.05)\end{array}$ & $\begin{array}{r}-0.09 \\
(0.09)\end{array}$ & $\begin{array}{r}-0.11 \\
(0.09)\end{array}$ \\
\hline
\end{tabular}

Notes: Significance levels: ${ }^{*} p<0.10,{ }^{* *} p<0.05,{ }^{* * *} p<0.01$. Robust standard errors in parentheses. The table presents the estimates of IV regressions for weighted voting power, in which we have excluded the top quartile (panel 1) and the bottom quartile (panel 2) from the jumps in voting power. Thus, panel 1 excludes all observations for which the absolute jump in voting power were larger than 0.183 (this includes all shifts in absolute majorities). Panel 2, then, excludes all the small changes in which the absolute jump was smaller than 0.036. The instrument is based on 200 perturbations of the vote vector using a variance of $1 \%$ of the vote count. Each regression contains population controls and council size, dummies for each party if it did not receive any votes, state-election dummies, and a polynomial control function that is quadratic in each party's vote share. The specification is estimated using municipality fixed effects. The number of observations in each regression is 4030. Source: Own calculations. 
Table 14: IV results voting power - end versus start of the election period

\begin{tabular}{|c|c|c|c|}
\hline & \multicolumn{3}{|c|}{ Local Taxes } \\
\hline & Trade Tax & Property Tax A & Property Tax B \\
\hline & 1 & 2 & 3 \\
\hline & \multicolumn{3}{|c|}{ Panel 1: Tax rates at the END of the election period } \\
\hline $\mathrm{SPD}$ & $\begin{array}{c}-0.24^{* *} \\
(0.10)\end{array}$ & $\begin{array}{c}-0.25 \\
(0.15)\end{array}$ & $\begin{array}{c}-0.20 \\
(0.16)\end{array}$ \\
\hline The Greens & $\begin{array}{c}-0.08 \\
(0.47)\end{array}$ & $\begin{array}{l}1.52^{* *} \\
(0.70)\end{array}$ & $\begin{array}{l}1.64^{* *} \\
(0.72)\end{array}$ \\
\hline FDP & $\begin{array}{c}0.46 \\
(0.91)\end{array}$ & $\begin{array}{c}-0.96 \\
(1.34)\end{array}$ & $\begin{array}{c}-2.77^{* *} \\
(1.38)\end{array}$ \\
\hline \multirow[t]{2}{*}{ Others } & $\begin{array}{c}0.02 \\
(0.07) \\
\end{array}$ & $\begin{array}{c}0.07 \\
(0.10) \\
\end{array}$ & $\begin{array}{c}0.08 \\
(0.11)\end{array}$ \\
\hline & \multicolumn{3}{|c|}{ Panel 2: Tax rates BEFORE the election period } \\
\hline SPD & $\begin{array}{c}0.05 \\
(0.07)\end{array}$ & $\begin{array}{c}-0.04 \\
(0.14)\end{array}$ & $\begin{array}{c}-0.04 \\
(0.14)\end{array}$ \\
\hline The Greens & $\begin{array}{c}-0.03 \\
(0.34)\end{array}$ & $\begin{array}{c}-0.91 \\
(0.61)\end{array}$ & $\begin{array}{c}-0.69 \\
(0.61)\end{array}$ \\
\hline FDP & $\begin{array}{c}0.31 \\
(0.65)\end{array}$ & $\begin{array}{c}0.88 \\
(1.18)\end{array}$ & $\begin{array}{c}0.92 \\
(1.18)\end{array}$ \\
\hline Others & $\begin{array}{c}-0.05 \\
(0.05)\end{array}$ & $\begin{array}{c}-0.18^{* *} \\
(0.09)\end{array}$ & $\begin{array}{c}-0.11 \\
(0.09)\end{array}$ \\
\hline
\end{tabular}

Notes: Significance levels: ${ }^{*} p<0.10,{ }^{* *} p<0.05,{ }^{* * *} p<0.01$. Robust standard errors in parentheses. The table shows the estimates of IV regressions for weighted voting power, in which the the tax rate outcomes are measured at the end of the election period (panel 1) and just before the start of the election period (panel 2). The instrument is based on 200 perturbations of the vote vector using a variance of $1 \%$ of the vote count. Each regression contains population controls and council size, dummies for each party if it did not receive any votes, state-election dummies, and a polynomial control function that is quadratic in each party's vote share. The specification is estimated using municipality fixed effects. The number of observations in each regression is 4030. Source: Own calculations. 
Table 15: Predicting the closeness of elections

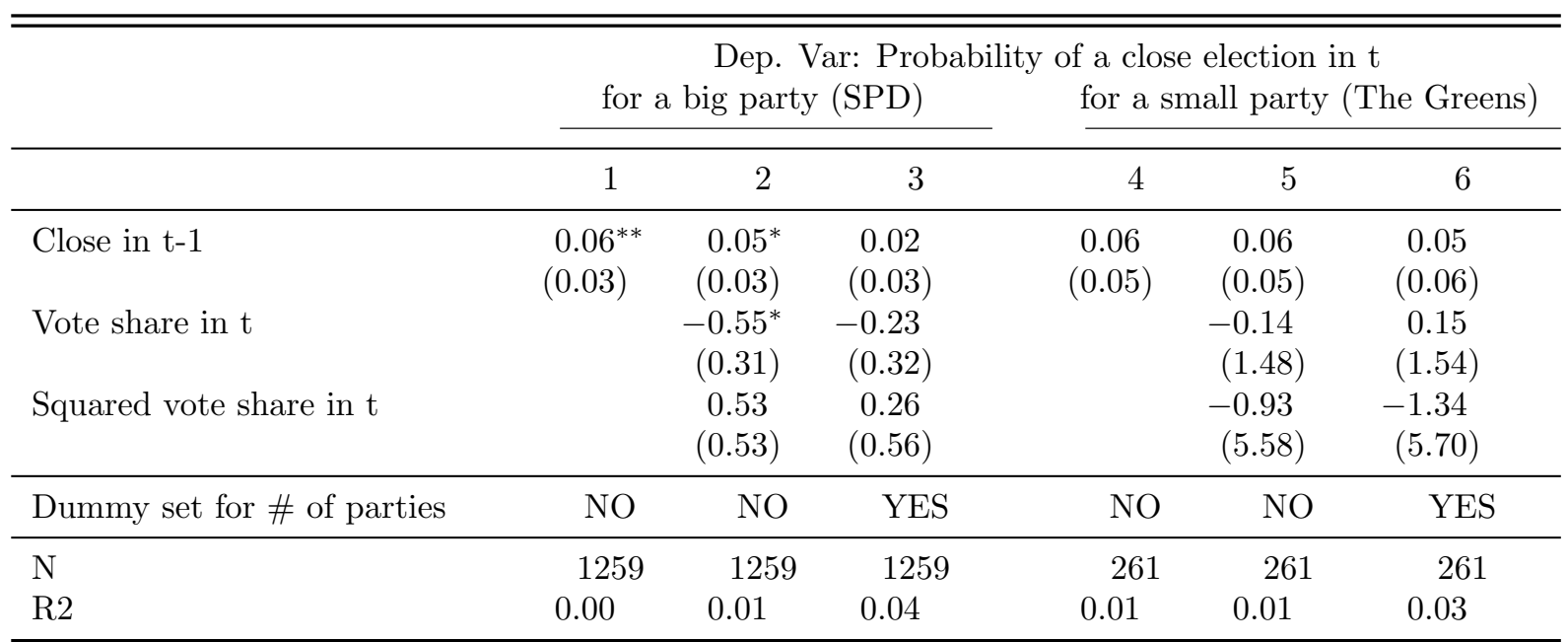

Notes: Significance levels: ${ }^{*} p<0.10,{ }^{*} p<0.05,{ }^{* * *} p<0.01$. In this table, we test the predictability of a close election event. For the data from Bavaria, we have linked the election results from 1996 to the ones in 2002 within each municipality. Conditional on participation in both elections, we ask whether the SPD (columns 1-3) or The Greens (columns 4-6) can predict that an election was close in 2002 if it was close in 1996. Columns 1 and 4 use closeness in 1996 as the only predictor for closeness in 2002. In column 2 and 5, we also control for the party's vote share (linear and squared) in 2002. A set of dummies indicating the number of parties that participated is added in columns 3 and 6. Source: Own calculations. 
Figure 2: Distribution of the instrument conditional on closeness
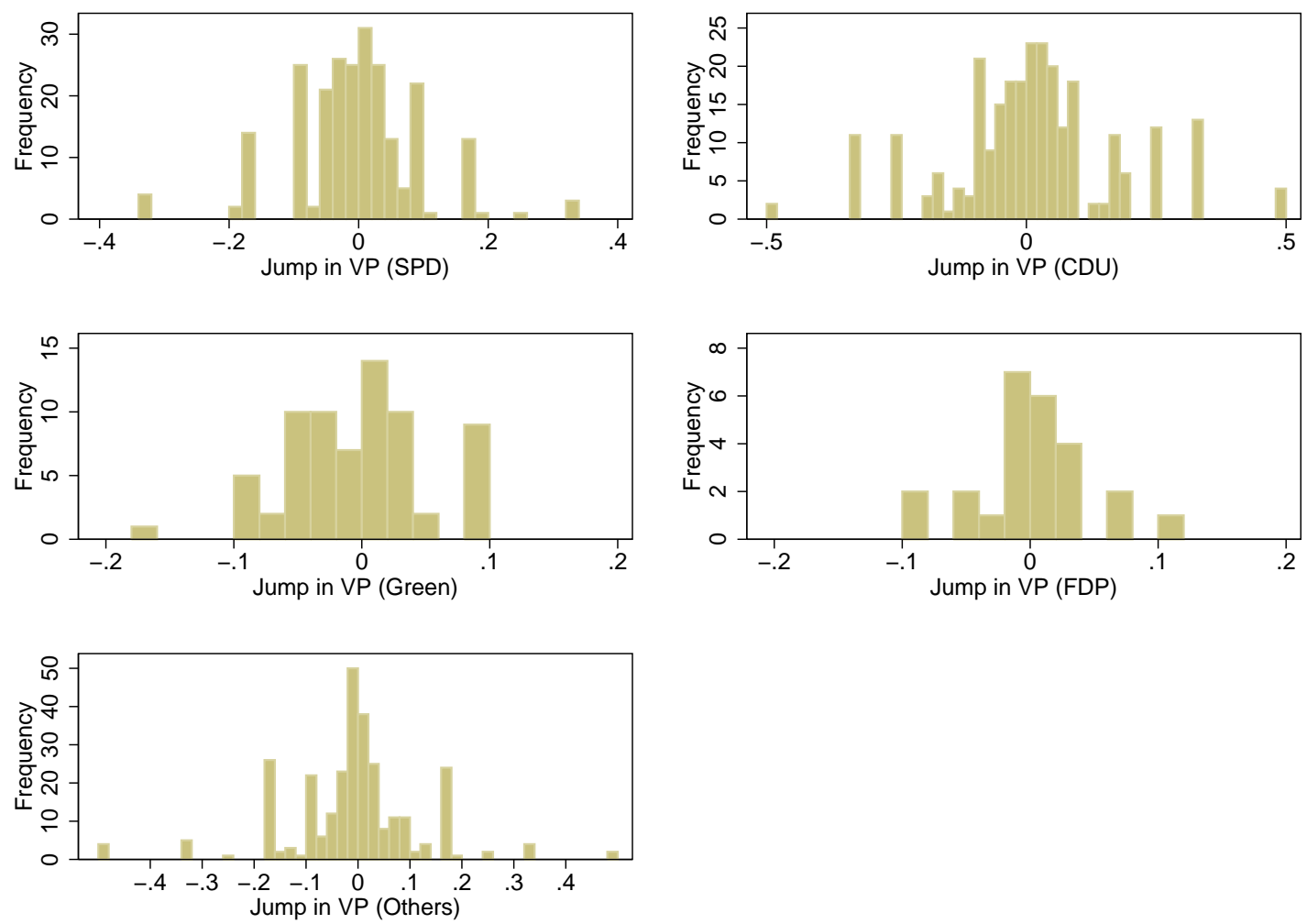

Notes: This figure graphically illustrates the distribution of the voting power jump that is used as instrument in the voting power analysis. The graph excludes all observations that were not coded as close elections. The five graphs show the distribution of each party respectively (as indicated below each graph). Note that, the graph for the "Others" (lower right) is special as it shows the aggregate mean of the instrument over the "Others" parties. Source: Own calculations. 
Figure 3: Distribution of vote share by sign of instrument
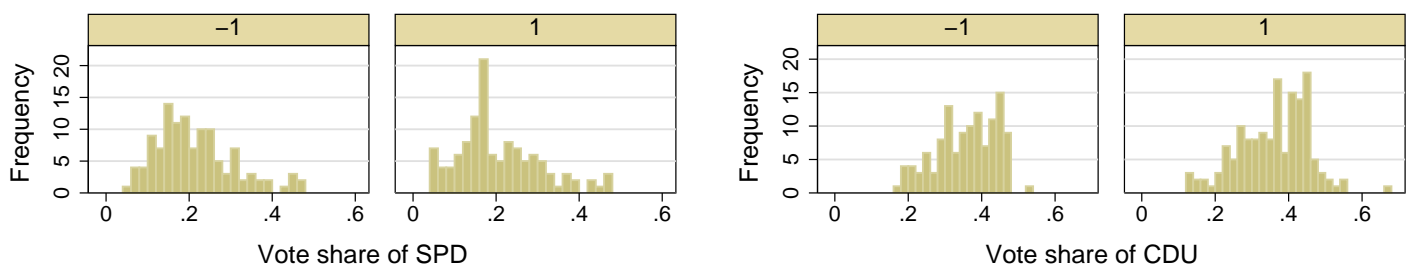

Graphs by djump_spd

Graphs by djump_cdu
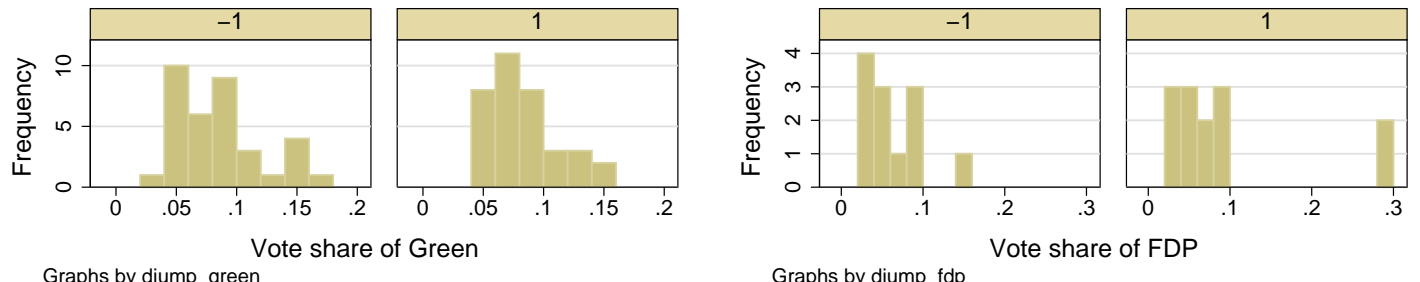

Graphs by djump_fdp

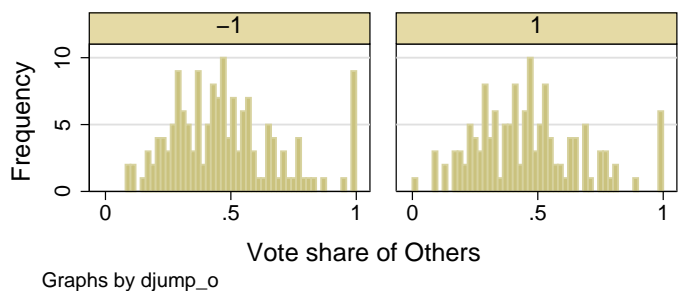

Notes: This figure graphically illustrates the distribution of the vote share of the respective parties separated into the distinct subsample when the instrument for voting power was positive or negative. A positive instrument indicates that an observation for this party has narrowly obtained the extra voting power (through one narrow seat), but was close to lose that seat. A negative instruments relates to the reverse accordingly. The graph excludes all observations that were not coded as close elections. The five different panels show the respective graphs for each party (as indicated below each graph). Note that, the graph for the "Others" (lower right) is special as it shows the aggregate vote share of all "Others" parties. Source: Own calculations. 